NBER WORKING PAPER SERIES

\title{
PUBLIC DEBT AND LOW INTEREST RATES
}

Olivier J. Blanchard

Working Paper 25621

http://www.nber.org/papers/w25621

\author{
NATIONAL BUREAU OF ECONOMIC RESEARCH \\ 1050 Massachusetts Avenue \\ Cambridge, MA 02138 \\ February 2019
}

No research support. The views expressed herein are those of the author and do not necessarily reflect the views of the National Bureau of Economic Research.

NBER working papers are circulated for discussion and comment purposes. They have not been peer-reviewed or been subject to the review by the NBER Board of Directors that accompanies official NBER publications.

(C) 2019 by Olivier J. Blanchard. All rights reserved. Short sections of text, not to exceed two paragraphs, may be quoted without explicit permission provided that full credit, including () notice, is given to the source. 
Public Debt and Low Interest Rates

Olivier J. Blanchard

NBER Working Paper No. 25621

February 2019

JEL No. E62

\begin{abstract}
This lecture focuses on the costs of public debt when safe interest rates are low. I develop four arguments.

First, I show that the current U.S. situation in which safe interest rates are expected to remain below growth rates for a long time, is more the historical norm than the exception. If the future is like the past, this implies that debt rollovers, that is the issuance of debt without a later increase in taxes may well be feasible. Put bluntly, public debt may have no fiscal cost.
\end{abstract}

Second, even in the absence of fiscal costs, public debt reduces capital accumulation, and may therefore have welfare costs. I show that welfare costs may be smaller than typically assumed. The reason is that the safe rate is the risk-adjusted rate of return to capital. If it is lower than the growth rate, it indicates that the risk-adjusted rate of return to capital is in fact low. The average risky rate however also plays a role. I show how both the average risky rate and the average safe rate determine welfare outcomes.

Third, I look at the evidence on the average risky rate, i.e. the average marginal product of capital. While the measured rate of earnings has been and is still quite high, the evidence from asset markets suggests that the marginal product of capital may be lower, with the difference reflecting either mismeasurement of capital or rents. This matters for debt: The lower the marginal product, the lower the welfare cost of debt.

Fourth, I discuss a number of arguments against high public debt, and in particular the existence of multiple equilibria where investors believe debt to be risky and, by requiring a risk premium, increase the fiscal burden and make debt effectively more risky. This is a very relevant argument, but it does not have straightforward implications for the appropriate level of debt.

My purpose in the lecture is not to argue for more public debt. It is to have a richer discussion of the costs of debt and of fiscal policy than is currently the case.

Olivier J. Blanchard

Peterson Institute for International Economics

1750 Massachusetts Avenue, NW

Washington, DC 20036

and NBER

oblanchard@piie.com

Appendices, programs, data are available at

https://piie.com/publications/working-papers/public-debt-and-low-interest-rates 


\title{
Public Debt and Low Interest Rates
}

\author{
Olivier Blanchard *
}

February 25, 2019

\section{Introduction}

Since 1980, interest rates on U.S. government bonds have steadily decreased. They are now lower than the nominal growth rate, and according to current forecasts, this is expected to remain the case for the foreseeable future. 10-year U.S. nominal rates hover around 3\%, while forecasts of nominal growth are around $4 \%$ ( $2 \%$ real growth, $2 \%$ inflation). The inequality holds even more strongly in the other major advanced economies: The 10-year UK nominal rate is $1.3 \%$, compared to forecasts of 10 -year nominal growth around $3.6 \%$ (1.6\% real, $2 \%$ inflation). The 10 -year Euro nominal rate is $1.2 \%$, compared to forecasts of 10-year nominal growth around $3.2 \%$ (1.5\% real,

\footnotetext{
${ }^{*}$ Peterson Institute for International Economics and MIT (oblanchard@piie.com) AEA Presidential Lecture, given in January 2019. Special thanks to Larry Summers for many discussions and many insights. Thanks for comments, suggestions, and data to Laurence Ball, Simcha Barkai, Charles Bean, Philipp Barrett, Ricardo Caballero, John Campbell, John Cochrane, Carlo Cottarelli, Peter Diamond, Stanley Fischer, Francesco Giavazzi, Robert Hall, Patrick Honohan, Anton Korinek, Larry Kotlikoff, Lorenz Kueng, Neil Mehrotra, Jonathan Parker, Thomas Philippon, Jim Poterba, Ricardo Reis, Dmitriy Sergeyev, Jay Shambaugh, Robert Solow, Jaume Ventura, Robert Waldmann, Philippe Weil, Ivan Werning, Jeromin Zettelmeyer, and many of my PIIE colleagues. Thanks for outstanding research assistance to Thomas Pellet, Colombe Ladreit, and Gonzalo Huertas. Appendixes, programs and data are available at https://piie.com/publications/ working-papers/public-debt-and-low-interest-rates
} 
$1.7 \%$ inflation). ${ }^{1}$ The 10 -year Japanese nominal rate is $0.1 \%$, compared to forecasts of 10-year nominal growth around $1.4 \%$ (1.0\% real, $0.4 \%$ inflation).

The question I ask in this lecture is what the implications of such low rates should be for government debt policy. It is an important question for at least two reasons. From a policy viewpoint, whether or not countries should reduce their debt, and by how much, is a central policy issue. From a theory viewpoint, one of pillars of macroeconomics is the assumption that people, firms, and governments are subject to intertemporal budget constraints. If the interest rate paid by the government is less than the growth rate, then the intertemporal budget constraint facing the government no longer binds. What the government can and should do in this case is definitely worth exploring.

The paper reaches strong, and, I expect, surprising, conclusions. Put (too) simply, the signal sent by low rates is not only that debt may not have a substantial fiscal cost, but also that it may have limited welfare costs.

Given that these conclusions are at odds with the widespread notion that government debt levels are much too high and must urgently be decreased, I consider several counterarguments, ranging from distortions, to the possibility that the future may be very different from the past, to multiple equilibria. All these arguments have merit, but they imply a different discussion from that dominating current discussions of fiscal policy.

The lecture is organized as follows.

Section 1 looks at the past behavior of U.S. interest rates and growth rates. It concludes that the current situation is actually not unusual. While interest rates on public debt vary a lot, they have on average, and in most decades, been lower than growth rates. If the future is like the past, the probability

\footnotetext{
${ }^{1}$ Different Euro countries have different government bond rates. The 10-year Euro nominal rate is a composite rate (with changing composition) constructed by the ECB.http: //sdw.ecb.europa.eu/quickview.do?SERIES_KEY=143.FM.M.U2.EUR.4F.BB.U2_10Y.YLD
} 
that the U.S. government can do a debt rollover-that it can issue debt and achieve a decreasing debt to GDP ratio without ever having to raise taxes later-is high.

That debt rollovers may be feasible does not imply however that they are desirable. Even if higher debt does not give rise later to a higher tax burden, it still has effects on capital accumulation, and thus on welfare. Whether and when higher debt increases or decreases welfare is taken up in Sections 2 and 3.

Section 2 looks at the effects of an intergenerational transfer (a conceptually simpler policy than a debt rollover, but a policy that shows most clearly the relevant effects at work) in an overlapping generation model with uncertainty. In the certainty context analyzed by Diamond (1965), whether such an intergenerational transfer from young to old is welfare improving depends on "the" interest rate, which in that model is simply the net marginal product of capital. If the interest rate is less than the growth rate, then the transfer is welfare improving. Put simply, in that case, a larger intergenerational transfer, or equivalently an increase in public debt, and thus less capital, is good.

When uncertainty is introduced however, the question becomes what interest rate we should look at to assess the welfare effects of such a transfer. Should it be the average safe rate, i.e. the rate on sovereign bonds (assuming no default risk), or should it be the average marginal product of capital? The answer turns out to be: Both.

As in the Diamond model, a transfer has two effects on welfare: an effect through reduced capital accumulation, and an indirect effect, through the induced change in the returns to labor and capital.

The welfare effect through lower capital accumulation depends on the safe rate. It is positive if, on average, the safe rate is less than the growth rate. The intuitive reason is that, in effect, the safe rate is the relevant risk- 
adjusted rate of return on capital, thus it is the rate that must be compared to the growth rate.

The welfare effect through the induced change in returns to labor and capital depends instead on the average (risky) marginal product of capital. It is negative if, on average, the marginal product of capital exceeds the growth rate.

Thus, in the current situation where it indeed appears that the safe rate is less than the growth rate, but the average marginal product of capital exceeds the growth rate, the two effects have opposite signs, and the effect of the transfer on welfare is ambiguous. The section ends with an approximation that shows most clearly the relative role of the two rates. The net effect may be positive, if the safe rate is sufficiently low and the average marginal product is not too high.

With these results in mind, Section 3 turns to numerical simulations. People live for two periods, working in the first, and retiring in the second. They have separate preferences vis-a-vis intertemporal substitution and risk. This allows to look at different combinations of risky and safe rates, depending on the degree of uncertainty and the degree of risk aversion. Production is CES in labor and capital, and subject to technological shocks: Being able to vary the elasticity of substitution between capital and labor turns out to be important as this elasticity determines the strength of the second effect on welfare. There is no technological progress, nor population growth, so the average growth rate is equal to zero.

I show how the welfare effects of a transfer can be positive or negative, and how they depend in particular on the elasticity of substitution between capital and labor. In the case of a linear technology (equivalently, an infinite elasticity of substitution between labor and capital), the rates of return, while random, are independent of capital accumulation, so that only the first effect is at work, and the safe rate is the only relevant rate in determin- 
ing the effect of the transfer on welfare. I then show how a lower elasticity of substitution implies a negative second effect, leading to an ambiguous welfare outcome.

I then turn to debt and show that a debt rollover differs in two ways from a transfer scheme. First, with respect to feasibility: So long as the safe rate remains less than the growth rate, the ratio of debt to GDP decreases over time; a sequence of adverse shocks may however increase the safe rate sufficiently so as to lead to explosive dynamics, with higher debt increasing the safe rate, and the higher safe rate in turn increasing debt over time. Second, with respect to desirability: A successful debt rollover can yield positive welfare effects, but less so than the transfer scheme. The reason is that a debt rollover pays people a lower rate of return than the implicit rate in the transfer scheme.

The conclusion of Section 3 is that the welfare effects of debt depend not only how on low the average safe rate is, but also on how high the average marginal product is. With this in mind, Section 4 returns to the empirical evidence on the marginal product of capital, focusing on two facts. The first fact is that the ratio of the earnings of U.S. corporations to their capital at replacement cost has remained high and relatively stable over time. This suggests a high marginal product, and thus, other things equal, a higher welfare cost of debt. The second fact, however, is that the ratio of the earnings of U.S. corporations to their market value has substantially decreased since the early 1980s. Put another way, Tobin's q, which is the ratio of the market value of capital to the value of capital at replacement cost, has substantially increased. There are two potential interpretations of this fact. First, that capital at replacement cost is poorly measured and does not fully capture intangible capital. Second, that an increasing proportion of earnings comes from rents. Both explanations (which are the subject of much current research) imply a lower marginal product for a given measured earnings rate, 
and thus a smaller welfare cost of debt.

Section 5 goes beyond the formal model and places the results in a broader but informal discussion of the costs and benefits of public debt.

On the benefit side, the model above has looked at debt issuance used to finance transfers in a full employment economy; this does not do justice to current policy discussions, which have focused on the role of debt finance to increase demand and output if the economy is in recession, and on the use of debt to finance public investment. This research has concluded that, if the neutral rate of interest is low and the effective lower bound on interest rates is binding, then there is a strong argument for using fiscal policy to sustain demand. The analysis above suggests that, in that very situation, the fiscal and welfare costs of higher debt may be lower than has been assumed, reinforcing the case for a fiscal expansion.

On the cost side, (at least) three arguments can be raised against the model above and its implications. The first is that the risk premium, and by implication the low safe rate relative to the marginal product of capital, may not reflect risk preferences but rather distortions, such as financial repression. Traditional financial repression, i.e. forcing banks to hold government bonds, is gone in the United States, but one may argue that agency issues within financial institutions or some forms of financial regulation such as liquidity ratios have similar effects. The second argument is that the future may be very different from the present, and the safe rate may turn out much higher than in the past. The third argument is the possibility of multiple equilibria, that if investors expect the government to be unable to fully repay the debt, they may require a risk premium which makes debt harder to pay back and makes their expectations self-fulfilling. I discuss all three arguments but focus mostly on the third. It is relevant and correct as far as it goes, but it is not clear what it implies for the level of public debt: Multiple equilibria typically hold for a large range of debt, and a realistic reduction in 
debt while debt remains in the range does not rule out the bad equilibrium. Section 6 concludes. To be clear: The purpose of the lecture is not to advocate for higher public debt, but to assess its costs. The hope is that this lecture leads to a richer discussion of fiscal policy than is currently the case.

\section{Interest rates, growth rates, and debt rollovers}

Interest rates on U.S. bonds have been and are still unusually low, reflecting in part the after-effects of the 2008 financial crisis and quantitative easing. The current (December 2018) 1-year T-bill nominal rate is $2.6 \%$, substantially below the most recent nominal growth rate, $4.8 \%$ (from the second to the third quarter of 2018, at annual rates)

The gap between the two is expected to narrow, but most forecasts and market signals have interest rates remaining below growth rates for a long time to come. Despite a strong fiscal expansion putting pressure on rates in an economy close to potential, the current 10 -year nominal rate remains around $3 \%$, while forecasts of nominal growth over the same period are around $4 \%$. Looking at real rates instead, the current 10 -year inflation-indexed rate is around $1 \%$, while most forecasts of real growth over the same period range from $1.5 \%$ to $2.5 \% .^{2}$

These forecasts come with substantial uncertainty.

Some argue that these low rates reflect "secular stagnation" forces that are likely to remain relevant for the foreseeable future. They point to structurally high saving and low investment, leading to a low equilibrium marginal product of capital for a long time to come (for example, Summers (2015), Rachel and Summers (2018). Others point to an increased demand for safe assets, leading to a lower safe rate for a given marginal product (for example,

\footnotetext{
${ }^{2}$ Since 1800, 10-year rolling sample averages of U.S. real growth have always been positive, except for one 10-year period, centered in 1930.
} 
Caballero, Farhi, and Gourinchas (2017a). An interesting attempt to identify the respective roles of marginal products, rents, and risk premia is given by Caballero, Farhi and Gourinchas (2017b).

Others point instead to factors such as aging in advanced economies, better social insurance or lower reserve accumulation in emerging markets, which may lead instead to higher rates in the future (for a discussion of the role of different factors, see for example Lukasz and Smith 2015, Lunsford and West (2018)) ${ }^{3}$.

Interestingly and importantly however, historically, interest rates lower than growth rates have been more the rule than the exception, making the issue of what debt policy should be under this configuration of more than temporary interest. I shall limit myself here to looking at the United States since 1950, but the conclusion holds for a large number of countries, over long periods of time. ${ }^{4}$

Figure 1 shows the evolution of the nominal GDP growth rate and the 1 -year Treasury bill rate. Figure 2 shows the evolution of the nominal GDP growth rate and the 10-year Treasury bond rate. Together, they have two

\footnotetext{
${ }^{3}$ Some have pointed to demographics as a factor likely to decrease the growth rate and increase the safe rate. Theory and evidence however suggest a more complex answer. A decrease in fertility implies a decrease in both the growth rate and the interest rate. An increase in longevity, unless accompanied by a proportional increase in the retirement age, may have no effect on the growth rate but lead to a decrease in the interest rate. Mehrotra and Sergeyev (2018), using a calibrated OLG model, derive and discuss the effects of population growth and productivity growth on the interest-growth rate differential. In current unpublished work, Carvalho et al, extending Carvalho et al (2016) and also using a calibrated OLG model, conclude thatdemographic evolutions are likely to lead to a lower neutral interest rate in the future.

${ }^{4}$ Two major data sets are those put together by Shiller (1992 and updates) for the United States since 1871, and by Jorda et al (2017) for 16 countries since 1870 . Based on these data, Mehrotra (2017) and Barrett (2017) show that the safe rate has been typically lower on average than the growth rate. Mauro et al (2015) look at the evidence from 55 countries since 1800. Their results, summarized in their Table 2, show that the safe interest rate has been on average lower than the growth rate, both for the group of advanced countries, and for the group of non-advanced economies. (For those who want to go back even further in time, data on the safe rate going back to the 14th century have been put together by Schmelzing (2018) and show a steady decrease in the rate over six centuries.)
} 
basic features:

Figure 1: Nominal GDP growth rate and 1-year T-bill rate, 1950-2018

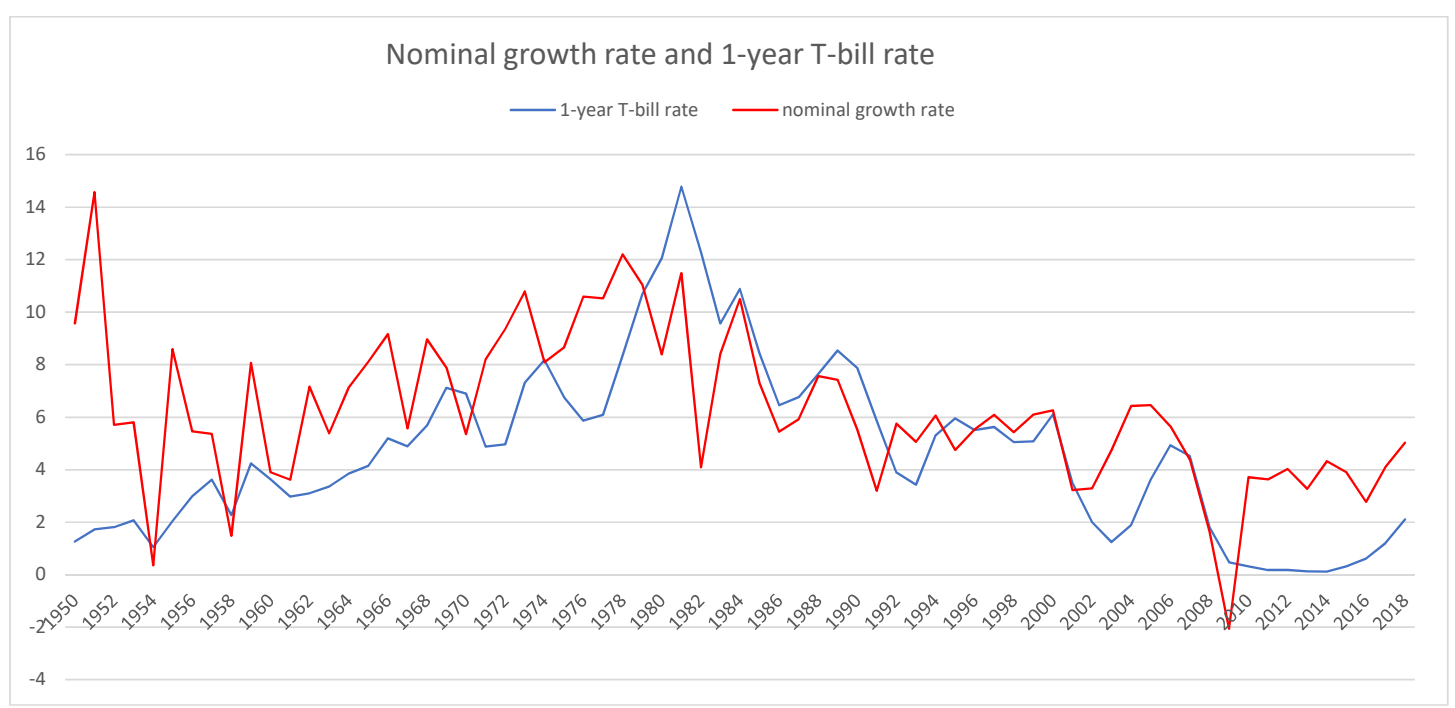

Figure 2: Nominal GDP growth rate and 10-year bond rate, 1950-2018

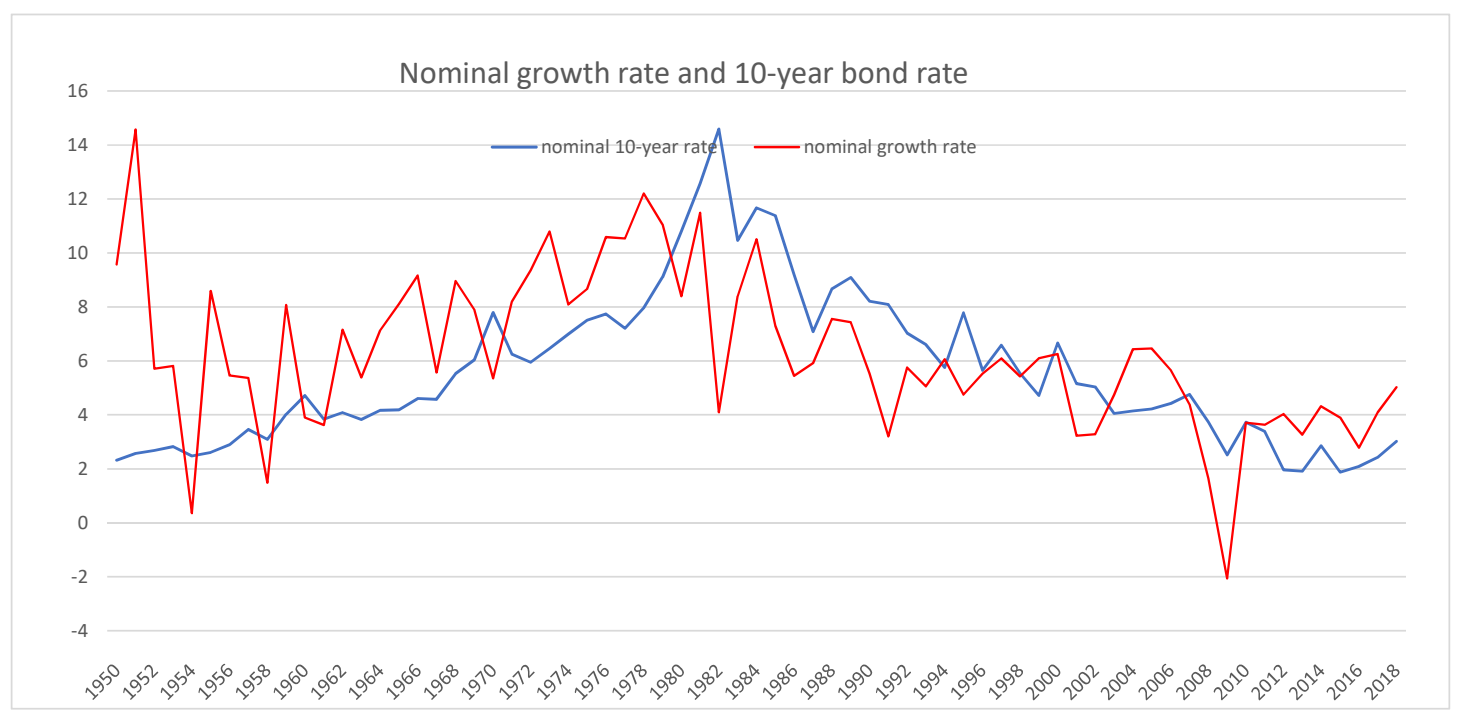


- On average, over the period, nominal interest rates have been lower than the nominal growth rate. ${ }^{5}$ The 1-year rate has averaged $4.7 \%$, the 10 -year rate has averaged $5.6 \%$, while nominal GDP growth has averaged $6.3 \%{ }^{6}$

- Both the 1-year rate and the 10-year rate were consistently below the growth rate until the disinflation of the early 1980s, Since then, both nominal interest rates and nominal growth rates have declined, with rates declining faster than growth, even before the financial crisis. Overall, while nominal rates vary substantially from year to year, the 1-year rate has been lower than the growth rate for all decades except for the 1980s. The 10-year rate has been lower than the growth rate for 4 out of 7 decades.

Given that my focus is on the implications of the joint evolution of interest rates and growth rates for debt dynamics, the next step is to construct a series for the relevant interest rate paid on public debt held by domestic private and foreign investors. I proceed in three steps (1) taking into account the maturity composition of the debt, (2) taking into account the tax payments on the interest received by the holders of public debt, and (3), taking into account Jensen's inequality. (Details of construction are given in appendix A. $)^{7}$

To take into account maturity, I use information on the average maturity of the debt held by private investors (that is excluding public institutions

\footnotetext{
${ }^{5}$ Equivalently, if one uses the same deflator, real interest rates have been lower than real growth rates. Real interest rates are however often computed using CPI inflation rather than the GDP deflator.

${ }^{6}$ Using Shiller's numbers for interest rates and historical BEA series for GDP, over the longer period 1871 to 2018 , the 1-year rate has averaged $4.6 \%$, the 10 -year rate $4.6 \%$ and nominal GDP growth $5.3 \%$.

${ }^{7} \mathrm{~A}$ more detailed construction of the maturity of the debt held by both private domestic and foreign investors is given in Hilscher et al (2018).
} 
and the Fed.) This average maturity went down from 8 years and 4 months in 1950 to 3 years and 4 months in 1974, with a mild increase since then to 5 years today. ${ }^{8}$ Given this series, I construct a maturity-weighted interest rate as a weighted average of the 1-year and the 10-year rates using $i_{t}=\alpha_{t} * i_{1, t}+$ $\left(1-\alpha_{t}\right) * i_{10, t}$ with $\alpha_{t}=(10-$ average maturity in years $) / 9$.

Many, but not all, holders of government bonds pay taxes on the interest paid, so the interest cost of debt is actually lower than the interest rate itself. There is no direct measure of those taxes, and thus I proceed as follows: ${ }^{910}$

I measure the tax rate of the marginal holder by looking at the difference between the yield on AAA municipal bonds (which are exempt from federal taxes) and the yield on a corresponding maturity Treasury bond, for both 1year and 10-year bonds, denoted $i_{m t 1}$ and $i_{m t 10}$ respectively. Assuming that the marginal investor is indifferent between holding the two, the implicit tax rate on 1-year Treasuries is given by $\tau_{1 t}=1-i_{m t 1} / i_{1 t}$, and the implicit tax rate on 10-year Treasuries is given by $\tau_{10 t}=1-i_{m t 10} / i_{10 t} .{ }^{11}$ The tax rate on 1 -year bonds peaks at about $50 \%$ in the late 1970 s (as inflation and nominal rates are high, leading to high effective tax rates), then goes down close to zero until the financial crisis, and has increased slightly since 2017. The tax rate on 10-year bonds follows a similar pattern, down from about $40 \%$ in the early 1980s to close to zero until the financial crisis, with a small increase

\footnotetext{
${ }^{8}$ Fed holdings used to be small, and limited to short maturity T-bills. As a result of quantitative easing, they have become larger and skewed towards long maturity bonds, implying a lower maturity of debt held by private investors than of total debt.

${ }^{9}$ For a parallel study, see Feenberg et al (2018).

${ }^{10}$ This is clearly only a partial equilibrium computation. To the extent that debt leads to lower capital accumulation and thus lower output, other tax revenues may decrease. To the extent however that consumption decreases less or even increases (as discussed in the next section), the effects depend on how much of taxation is output based or consumption based.

${ }^{11}$ This is an approximation. On the one hand, the average tax rate is likely to exceed this marginal rate. On the other hand, to the extent that municipal bonds are also partially exempt from state taxes, the marginal tax rate may reflect in part the state tax rate in addition to the Federal tax rate.
} 
since 2016. ${ }^{12}$ Taking into account the maturity structure of the debt, I then construct an average tax rate in the same way as I constructed the interest rate above, by constructing $\tau_{t}=\alpha_{t} * \tau_{1, t}+\left(1-\alpha_{t}\right) * \tau_{10, t}$

Not all holders of Treasuries pay taxes however. Foreign holders, private and public (such as central banks), Federal retirement programs and Fed holdings are not subject to tax. The proportion of such holders has steadily increased over time, reflecting the increase in emerging markets' reserves (in particular China's), the growth of the Social Security Trust Fund, and more recently, the increased holdings of the Fed, among other factors. From 15\% in 1950 , it now accounts for $64 \%$ today.

Using the maturity adjusted interest rate from above, $i_{t}$, the implicit tax rate, $\tau_{t}$, and the proportion of holders likely subject to tax, $\beta_{t}$, I construct an "adjusted interest rate" series according to:

$$
i_{a d j, t}=i_{t}\left(1-\tau_{t} * \beta_{t}\right)
$$

Its characteristics are shown in Figures 3 and 4 . Figure 3 plots the adjusted rate against the 1-year and the 10-year rates. Figure 4 plots the adjusted tax rate against the nominal growth rate. They yield two conclusions:

- First, over the period, the average adjusted rate has been lower than either the 1 -year or the 10 -year rates, averaging $3.8 \%$ since 1950 . This however largely reflects the non neutrality of taxation to inflation in the 1970 s and 1980s, which is much less of a factor today. In 2018, the rate was around $2.4 \%$.

- Second, over the period, the average adjusted rate has been substantially lower than the average nominal growth rate, $3.8 \%$ versus $6.3 \%$.

\footnotetext{
${ }^{12}$ The computed tax rates are actually negative during some of the years of the Great Recession, presumably reflecting the effects of Quantitative Easing. I put them equal to zero for those years
} 
Figure 3: 1-year rate, 10-year rate, and adjusted rate, 1950-2018

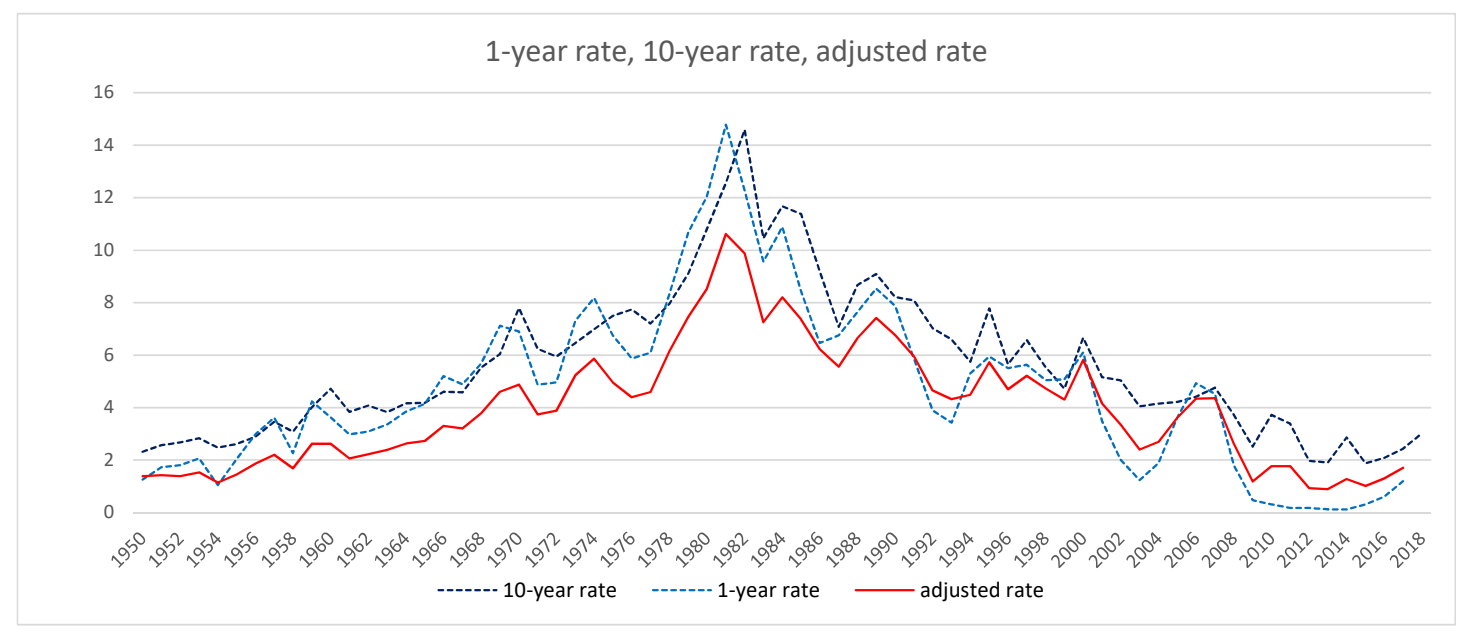

Figure 4: Nominal GDP growth rate and adjusted rate, 1950-2018

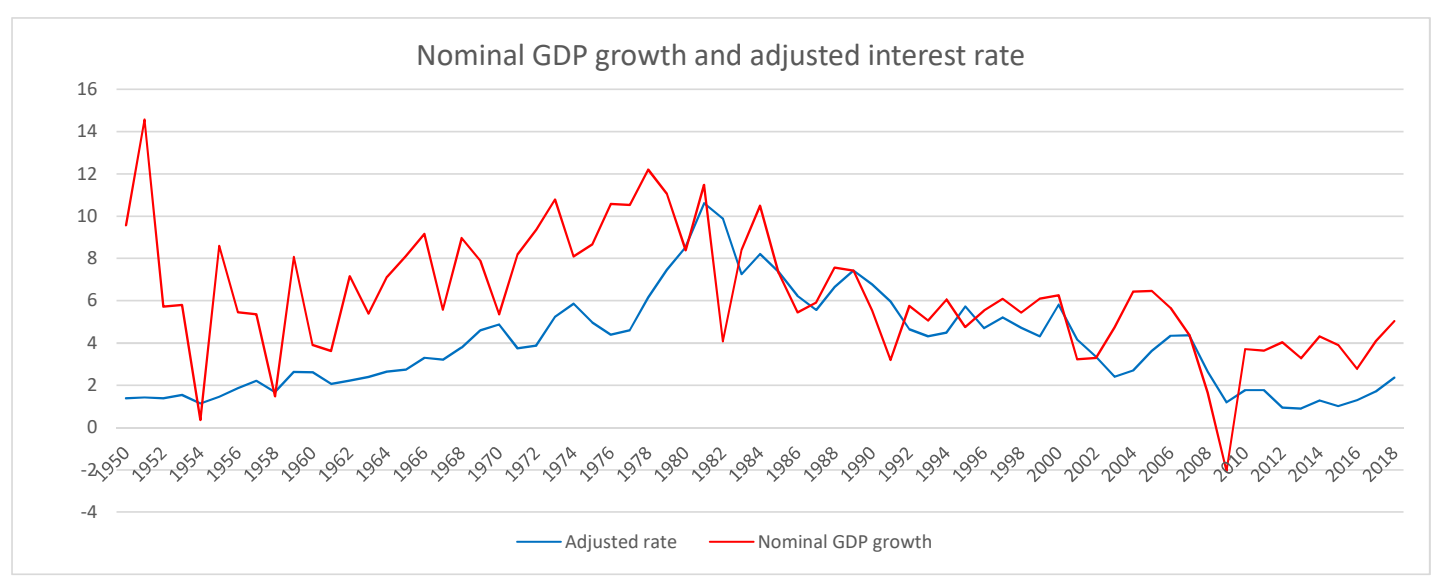

The last potential issue is Jensen's inequality. The dynamics of the ratio of debt to GDP are given by:

$$
d_{t}=\frac{1+r_{a d j, t}}{1+g_{t}} d_{t-1}+x_{t}
$$


where $d_{t}$ is the ratio of debt to GDP (with both variables either in nominal or in real terms if both are deflated by the same deflator), and $x_{t}$ is the ratio of the primary deficit to GDP (again, with both variables either in nominal or in real terms). The evolution of the ratio depends on the relevant product of interest rates and growth rates (nominal or real) over time.

Given the focus on debt rollovers-that is the issuance of debt without a later increase in taxes or reduction in spending - suppose we want to trace debt dynamics under the assumption that $x_{t}$ remains equal to zero. ${ }^{13}$ Suppose that $\ln \left[\left(1+r_{a d j, t}\right) /\left(1+g_{t}\right)\right]$ is distributed normally with mean $\mu$ and variance $\sigma^{2}$. Then, the evolution of the ratio will depend not on $\exp \mu$ but on $\exp \left(\mu+(1 / 2) \sigma^{2}\right)$. We have seen that, historically, $\mu$ was between $-1 \%$ and $2 \%$. The standard deviation of the log ratio over the same sample is equal to $2.8 \%$, implying a variance of $0.08 \%$, thus too small to affect the conclusions substantially. Jensen's inequality is thus not an issue here. ${ }^{14}$

In short, if we assume that the future will be like the past (admittedly a big if), debt rollovers appear feasible. While the debt ratio may increase for some time due to adverse shocks to growth or positive shocks to the interest rate, it will eventually decrease over time. In other words, higher debt may not imply a higher fiscal cost.

In this light, it is interesting to do the following counterfactual exercise. ${ }^{15}$ Assume that the debt ratio in year $t$ was what it actually was, but that the primary balance was equal to zero from then on, so that debt in year $t+n$ was given by:

\footnotetext{
${ }^{13}$ Given that we subtract taxes on interest from interest payments, the primary balance must also be computed subtracting those tax payments.

${ }^{14}$ The conclusion is the same if we do not assume log normality, but rather bootstrap from the actual distribution, which has slightly fatter tails.

${ }^{15}$ For related computations and related conclusions, see Mehrotra and Sergeyev (2018).
} 
Figure 5: Debt dynamics, with zero primary balance, starting in year $t$, using the non-tax adjusted rate

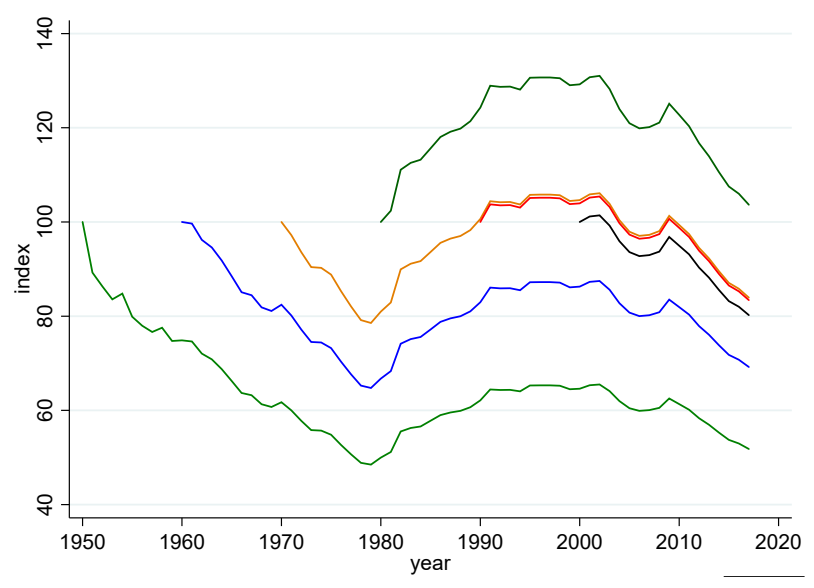

Figure 6: Debt dynamics, with zero primary balance, starting in year $t$, using the tax-adjusted rate

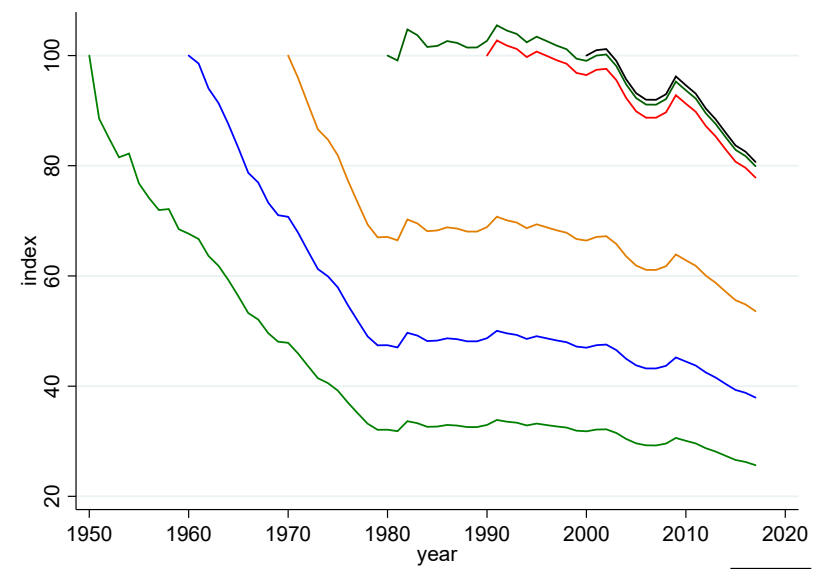

$$
d_{t+n}=\left(\prod_{i=1}^{i=n} \frac{1+r_{a d j, t+i}}{1+g_{t+i}}\right) d_{t}
$$

Figures 5 and 6 show what the evolution of the debt ratio would have 
been, starting at different dates in the past. For convenience, the ratio is normalized to 100 at each starting date. Figure 5 uses the non-tax adjusted rate, and Figure 6 uses the tax-adjusted interest rate.

Figure 5 shows that, for each starting date, the debt ratio would eventually have decreased, even in the absence of a primary surplus. The decrease, if starting in the 1950s, 1960s, or 1970s, is quite dramatic. But the figure also shows that a series of bad shocks, such as happened in the 1980s, can increase the debt ratio to higher levels for a while.

Figure 6, which I believe is the more appropriate one, gives an even more optimistic picture, where the debt ratio rarely would have increased, even in the 1980s - the reason being the higher tax revenues associated with inflation during that period.

What these figures show is that, historically, debt rollovers would have been feasible. Put another way, it shows that the fiscal cost of higher debt would have been small, if not zero. This is at striking variance with the current discussions of fiscal space, which all start from the premise that the interest rate is higher than the growth rate, implying a tax burden of the debt.

The fact that debt rollovers may be feasible (i.e. that they may not have a fiscal cost) does not imply however that they are desirable (that they have no welfare cost). This is the topic taken up in the next two sections.

\section{Intergenerational transfers and welfare}

Debt rollovers are, by their nature, non-steady-state phenomena, and have potentially complex dynamics and welfare effects. It is useful to start by looking at a simpler policy, namely a transfer from the young to the old (equivalent to pay-as-you-go social security), and then to return to debt and debt rollovers in the next section.

The natural set-up to explore the issues is an overlapping generation model 
under uncertainty. The overlapping generation structure implies a real effect of intergenerational transfers or debt, and the presence of uncertainty allows to distinguish between the safe rate and the risky marginal product of capital. ${ }^{16}$

I proceed in two steps, first briefly reviewing the effects of a transfer under certainty, following Diamond (1965), then extending it to allow for uncertainty. (Derivations are given in Appendix B) ${ }^{17} 18$

Assume that the economy is populated by people who live for two periods, working in the first period, and consuming in both periods. Their utility is given by:

$$
U=(1-\beta) U\left(C_{1}\right)+\beta U\left(C_{2}\right)
$$

where $C_{1}$ and $C_{2}$ are consumption in the first and the second period of life respectively. (As I limit myself for the moment to looking at the effects of the transfer on utility in steady state, there is no need for now for a time index.) Their first and second period budget constraints are given by

\footnotetext{
${ }^{16}$ In this framework, the main general equilibrium effect of intergenerational transfers or debt is to decrease capital accumulation. A number of recent papers have explored the effects of public debt when public debt also provides liquidity services. Aiyagari and McGrattan (1998) for example explore the effects of public debt in an economy in which agents cannot borrow and thus engage in precautionary saving; in that framework, debt relaxes the borrowing constraint and decreases capital accumulation. Angeletos, Collard and Dellas (2016) develop a model where public debt provides liquidity. In that model, debt can either crowd out capital, for the same reasons as in Aiyagari and McGrattan, or crowd in capital by increasing the available collateral required for investment. These models are obviously very different from the model presented here, but they share a focus on the low safe rate as a signal about the desirability of public debt. Finally, to the extent that it focuses on economies where the safe rate may be less than the growth rate, it is related to the literature on rational bubbles in dynamically efficient economies with financial frictions, for example Martin and Ventura (2016), or Farhi and Tirole (2012).

${ }^{17}$ For a nice introduction to the logic and implications of the overlapping generation model, see Weil (2008).

${ }^{18}$ After the lecture was delivered, I was made aware of unpublished notes by Waldman (2016), which explore a closely related model under different forms of uncertainty and also show that the welfare effects of debt depend in general on both the safe and the risky rate.
} 


$$
C_{1}=W-K-D ; C_{2}=R K+D
$$

where $W$ is the wage, $K$ is saving (equivalently, next period capital), $D$ is the transfer from young to old, and $R$ is the rate of return on capital.

I ignore population growth and technological progress, so the growth rate is equal to zero. Production is given by a constant returns production function:

$$
Y=F(K, N)
$$

It is convenient to normalize labor to 1 , so $Y=F(K, 1)$. Both factors are paid their marginal product.

The first order condition for utility maximisation is given by:

$$
(1-\beta) U^{\prime}\left(C_{1}\right)=\beta R U^{\prime}\left(C_{2}\right)
$$

The effect of a small increase in the transfer $D$ on utility is given by:

$$
d U=\left[-(1-\beta) U^{\prime}\left(C_{1}\right)+\beta U^{\prime}\left(C_{2}\right)\right] d D+\left[(1-\beta) U^{\prime}\left(C_{1}\right) d W+\beta K U^{\prime}\left(C_{2}\right) d R\right]
$$

The first term in brackets, call it $d U_{a}$, represents the partial equilibrium, direct, effect of the transfer; the second term, call it $d U_{b}$, represents the general equilibrium effect of the transfer through the induced change in wages and rates of return.

Consider the first term, the effect of debt on utility given labor and capital prices. Using the first-order condition gives: 


$$
d U_{a}=\left[\beta\left(-R U^{\prime}\left(C_{2}\right)+U^{\prime}\left(C_{2}\right)\right)\right] d D=\beta(1-R) U^{\prime}\left(C_{2}\right) d D
$$

So, if $R<1$ (the case known as "dynamic inefficiency"), then, ignoring the other term, a small increase in the transfer increases welfare. The explanation is straightforward: If $R<1$, the transfer gives a higher rate of return to savers than does capital.

Take the second term, the effect of debt on utility through the changes in $W$ and $R$. An increase in debt decreases capital and thus decreases the wage and increases the rate of return on capital. What is the effect on welfare?

Using the factor price frontier relation $d W / d R=-K / N$,or equivalently $d W=-K d R$ (given that $N=1$ ), rewrite this second term as:

$$
d U_{b}=-\left[(1-\beta) U^{\prime}\left(C_{1}\right)-\beta U^{\prime}\left(C_{2}\right)\right] K d R
$$

Using the first order condition for utility maximization gives:

$$
d U_{b}=-\left[\beta(R-1) U^{\prime}\left(C_{2}\right)\right] K d R
$$

So, if $R<1$ then, just like the first term, a small increase in the transfer increases welfare (as the lower capital stock leads to an increase in the interest rate). The explanation is again straightforward: Given the factor price frontier relation, the decrease in the capital leads to an equal decrease in income in the first period and increase in income in the second period. If $R<1$, this is more attractive than what capital provides, and thus increases welfare.

Using the definition of the elasticity of substitution $\eta \equiv\left(F_{K} F_{N}\right) / F_{K N} F$, the definition of the share of labor, $\alpha=F_{N} / F$, and the relation between second derivatives of the production function, $F_{N K}=-K F_{K K}$, this second term can be rewritten as: 


$$
d U_{b}=[\beta(1 / \eta) \alpha]\left[(R-1) U^{\prime}\left(C_{2}\right)\right] R d K
$$

Note the following two implications of equations (1) and (2):

- The sign of the two effects depends on $R-1$. If $R<1$, then a decrease in capital accumulation increases utility. In other words, if the marginal product is less than the growth rate (which here is equal to zero), an intergenerational transfer has a positive effect on welfare in steady state.

- The strength of the second effect depends on the elasticity of substitution $\eta$. If for example $\eta=\infty$ so the production function is linear and capital accumulation has no effect on either wages or rates of return to capital, this second effect is equal to zero.

So far, I just replicated the analysis in Diamond. ${ }^{19}$ Now I introduce uncertainty in production, so the marginal product of capital is uncertain. If people are risk averse, the average safe rate will be less than the average marginal product of capital. The basic question becomes:

What is the relevant rate we should look at for welfare purposes? Put loosely, is it the average marginal product of capital $E R$, or is it the average safe rate $E R^{f}$, or is it some other rate altogether?

The model is the same as before, except for the introduction of uncertainty:

People born at time $t$ have expected utility given by (I now need time subscripts as the steady state is stochastic):

$$
U_{t} \equiv(1-\beta) U\left(C_{1, t}\right)+\beta E U\left(C_{2, t+1}\right)
$$

\footnotetext{
${ }^{19}$ Formally, Diamond looks at the effects of a change in debt rather than a transfer. But, under certainty and in steady state, the two are equivalent.
} 
Their budget constraints are given by

$$
C_{1 t}=W_{t}-K_{t}-D ; C_{2 t+1}=R_{t+1} K_{t}+D
$$

Production is given by a constant returns production function

$$
Y_{t}=A_{t} F\left(K_{t-1}, N\right)
$$

where $N=1$ and $A_{t}$ is stochastic. (The capital at time $t$ reflects the saving of the young at time $t-1$, thus the timing convention).

At time $t$, the first order condition for utility maximization is given by:

$$
(1-\beta) U^{\prime}\left(C_{1, t}\right)=\beta E\left[R_{t+1} U^{\prime}\left(C_{2, t+1}\right)\right]
$$

We can now define a shadow safe rate $R_{t+1}^{f}$, which must satisfy:

$$
R_{t+1}^{f} E\left[U^{\prime}\left(C_{2, t+1}\right]=E\left[R_{t+1} U^{\prime}\left(C_{2, t+1}\right)\right]\right.
$$

Now consider a small increase in $D$ on utility at time $t$ :

$d U_{t}=\left[-(1-\beta) U^{\prime}\left(C_{1, t}\right)+\beta E U^{\prime}\left(C_{2, t+1}\right)\right] d D+\left[(1-\beta) U^{\prime}\left(C_{1, t}\right) d W_{t}+\beta K_{t} E\left[U^{\prime}\left(C_{2, t+1}\right) d R_{t+1}\right]\right]$

As before, the first term in brackets, call it $d U_{a t}$, reflects the partial equilibrium, direct, effect of the transfer, the second term, call it $d U_{b t}$, reflects the general equilibrium effect of the transfer through the change in wages and rates of return to capital.

Take the first term, the effect of debt on utility given prices. Using the first order condition gives: 


$$
d U_{a t}=\left[-\beta E\left[R_{t+1} U^{\prime}\left(C_{2, t+1}\right)\right]+\beta E\left[U^{\prime}\left(C_{2, t+1}\right)\right]\right] d D
$$

So, using the definition of the safe rate:

$$
d U_{a t}=\beta\left(1-R_{t+1}^{f}\right) E U^{\prime}\left(C_{2, t+1}\right) d D
$$

So, to determine the sign effect of the transfer on welfare through this first channel, the relevant rate is indeed the safe rate. In any period in which $R_{t+1}^{f}$ is less than one, the transfer is welfare improving.

The reason why the safe rate is what matters is straightforward and important: The safe rate is, in effect, the risk-adjusted rate of return on capital. $^{20}$ The intergenerational transfer gives people a higher rate of return to people than the risk-adjusted rate of return on capital.

Take the second term, the effect of the transfer on utility through prices:

$$
d U_{b t}=(1-\beta) U^{\prime}\left(C_{1, t}\right) d W_{t}+\beta E\left[U^{\prime}\left(C_{2, t+1}\right) K_{t} d R_{t+1}\right]
$$

Or using the factor price frontier relation:

$$
d U_{b t}=-(1-\beta) U^{\prime}\left(C_{1, t}\right) K_{t-1} d R_{t}+\beta E\left[U^{\prime}\left(C_{2, t+1}\right) K_{t} d R_{t+1}\right]
$$

In general, this term will depend both on $d K_{t-1}$ (which affects $d W_{t}$ ) and on $d K_{t}$ (which affects $d R_{t+1}$ ). If we evaluate it at $K_{t}=K_{t-1}=K$ and $d K_{t}=$ $d K_{t+1}=d K$, it can be rewritten, using the same steps as in the certainty case, as:

$$
d U_{b t}=[\beta(1 / \eta) \alpha] E\left[\left(R_{t+1}-\frac{R_{t+1}}{R_{t}}\right) U^{\prime}\left(C_{2, t+1}\right)\right] R_{t} d K
$$

\footnotetext{
${ }^{20}$ The relevance of the safe rate in assessing the return to capital accumulation was one of the themes in Summers (1990).
} 
Or:

$$
d U_{b t}=[\beta(1 / \eta) \alpha] E\left[\left(R_{t+1} U^{\prime}\left(C_{2, t+1}\right)\right]\left(R_{t}-1\right) d K\right.
$$

Thus the relevant rate in assessing the sign of the welfare effect of the transfer through this second term is the risky rate, the marginal product of capital. If $R_{t}$ is less than one, the implicit transfer due to the change in input prices increases utility. If $R_{t}$ is greater than one, the implicit transfer decreases utility.

The reason why it is the risky rate that matters is simple. Capital yields a rate of return $R_{t+1}$. The change in prices due to the decrease in capital represents an implicit transfer with rate of return $R_{t+1} / R_{t}$. Thus, whether the implicit transfer increases or decreases utility depends on whether $R_{t}$ is less or greater than one.

Putting the two sets of results together: If the safe rate is less than one, and the risky rate is greater than one-the configuration that appears to be relevant today - the two terms now work in opposite directions: The first term implies that an increase in debt increases welfare. The second term implies that an increase in debt instead decreases welfare. Both rates are thus relevant.

To get a sense of relative magnitudes of the two effects, and therefore which one is likely to dominate, the following approximation is useful: Evaluate the two terms at the average values of the safe and the risky rates, to get:

$$
d U / d D=\left[\left(1-E R^{f}\right)-(1 / \eta) \alpha E R^{f}(E R-1)(-d K / d D)\right] \beta E\left[U^{\prime}\left(C_{2}\right)\right]
$$

so that: 


$$
\text { sign } d U \equiv \operatorname{sign}\left[\left(1-E R^{f}\right)-(1 / \eta) \alpha E R^{f}(-d K / d D)(E R-1)\right]
$$

where, from the accumulation equation, we have the following approximation: ${ }^{21}$

$$
d K / d D \approx-\frac{1}{1-\beta \alpha(1 / \eta) E R}
$$

Note that, if the production is linear, and so $\eta=\infty$, the second term in equation (6) is equal to zero, and the only rate that matters is $E R^{f}$. Thus, if $E R^{f}$ is less than one, a higher transfer increases welfare. As the elasticity of substitution becomes smaller, the price effect becomes stronger, and, eventually, the welfare effect changes sign and becomes negative.

In the Cobb-Douglas case, using the fact that $E R \approx(1-\alpha) /(\alpha \beta)$, (the approximation comes from ignoring Jensen's inequality) the equation reduces to the simpler formula:

$$
\operatorname{sign} d U \equiv \operatorname{sign}\left[\left(1-E R^{f} E R\right)\right]
$$

Suppose that the average annual safe rate is $2 \%$ lower than the growth rate, so that $E R^{f}$, the gross rate of return over a unit period—say 25 years-is $0.98^{25}=0.6$, then the welfare effect of a small increase in the transfer is positive if $E R$ is less than 1.66, or equivalently, if the average annual marginal product is less than $2 \%$ above the growth rate. ${ }^{22}$

\footnotetext{
${ }^{21}$ This is an approximation in two ways. It ignores uncertainty and assumes that the direct effect of the transfer on saving is 1 for 1 , which is an approximation.

${ }^{22}$ Note that the economy we are looking at may be dynamically efficient in the sense of Zilcha (1991). Zilcha defined dynamic efficiency as the condition that there is no reallocation such that consumption of either the young or the old can be increased in at least one state of nature and one period, and not decreased in any other; the motivation for the definition is that it makes the condition independent of preferences. He then showed that in a stationary economy, a necessary and sufficient condition for dynamic inefficiency is that $E \ln R>0$. What the argument in the text has shown is that an intergenerational transfer
} 
Short of a much richer model, it is difficult to know how reliable these rough computations are as a guide to reality. The model surely overstates the degree of non-Ricardian equivalence: Debt in this economy is (nearly fully) net wealth, even if $R^{f}$ is greater than one and the government must levy taxes to pay the interest to keep the debt constant. The assumption that capital and labor are equally risky may not be right: Holding claims to capital (i.e. shares) involves price risk, which is absent from the model as capital fully depreciates within a period; on the other hand, labor income, in the absence of insurance against unemployment, can also be very risky. Another restrictive assumption of the model is that the economy is closed: In an open economy, the effect on capital is likely to be smaller, with changes in public debt being partly reflected in increases in external debt. I return to the issue when discussing debt (rather than intertemporal transfers) later. Be this as it may, the analysis suggests that the welfare effects of a transfer may not necessarily be adverse, or, if adverse, may not be very large.

\section{Simulations. Transfers, debt, and debt rollovers}

To get a more concrete picture, and turn to the effects of debt and debt rollovers requires going to simulations. ${ }^{23}$ Within the structure of the model above, I make the following specific assumptions: (derivations and details of

can be welfare improving even if the Zilcha condition holds: As we saw, expected utility can increase even if the average risky rate is large, so long as the safe rate is low enough. The reallocation is such that consumption indeed decreases in some states, yet expected utility is increased.

${ }^{23}$ One can make some progress analytically, and, in Blanchard and Weil (2001), we did characterize the behavior of debt at the margin (that is, taking the no-debt prices as given), for a number of different utility and production functions and different incomplete market structures. We only focused on debt dynamics however, and not on the normative implications. 
simulations are given in Appendix C.)

I think of each of the two periods of life as equal to 25 years. Given the role of risk aversion in determining the gap between the average safe and risky rates, I want to separate the elasticity of substitution across the two periods of life and the degree of risk aversion. Thus I assume that utility has an Epstein-Zin-Weil representation of the form (Epstein and Zin(2013), Weil (1990)):

$$
(1-\beta) \ln C_{1, t}+\beta \frac{1}{1-\gamma} \ln E\left(C_{2, t+1}^{1-\gamma}\right)
$$

The log-log specification implies that the intertemporal elasticity of substitution is equal to 1 . The coefficient of relative risk aversion is given by $\gamma$.

As the strength of the second effect above depends on the elasticity of substitution between capital and labor, I assume that production is characterized by a constant elasticity of substitution production function, with multiplicative uncertainty:

$$
Y_{t}=A_{t}\left(b K_{t-1}^{\rho}+(1-b) N^{\rho}\right)^{1 / \rho}=A_{t}\left(b K_{t-1}^{\rho}+(1-b)\right)^{1 / \rho}
$$

where $A_{t}$ is white noise and is distributed $\log$ normally, with $\ln A_{t} \sim \mathcal{N}\left(\mu ; \sigma^{2}\right)$ and $\rho=(\eta-1) / \eta$, where $\eta$ is the elasticity of substitution. When $\eta=\infty, \rho=1$ and the production function is linear.

Finally, I assume that, in addition to the wage, the young receive a nonstochastic endowment, $X$. Given that the wage follows a log normal distribution and thus can be arbitrarily small, such an endowment is needed to make sure that the deterministic transfer from the young to the old is always feasible, no matter what the realization of $W{ }^{24}$ I assume that the endowment is equal to $100 \%$ of the average wage absent the transfer.

\footnotetext{
${ }^{24}$ Alternatively, a lower bound on the wage distribution will work as well. But this would imply choosing an other distribution than the log normal.
} 
Given the results in the previous section, I calibrate the model so as to fit a set of values for the average safe rate and the average risky rate. I consider average net annual risky rates (marginal products of capital) minus the growth rate (here equal to zero) between $0 \%$ and $4 \%$. These imply values of the average 25-year gross risky rate, $E R$, between 1.00 and 2.66. I consider average net annual safe rates minus the growth rate between $-2 \%$ and $1 \%$; these imply values of the average 25-year gross safe rate, $E R^{f}$, between 0.60 and 1.28 .

I choose some of the coefficients a priori. I choose $b$ (which is equal to the capital share in the Cobb-Douglas case) to be $1 / 3$. For reasons explained below, I choose the annual value of $\sigma_{a}$ to be a high $4 \%$ a year, which implies a value of $\sigma$ of $\sqrt{25} * 4 \%=0.20$.

Because the strength of the second effect above depends on the elasticity of substitution, I consider two different values of $\eta, \eta=\infty$ which corresponds to the linear production function case, and in which the price effects of lower capital accumulation are equal to zero, and $\eta=1$, the Cobb-Douglas case, which is generally seen as a good description of the production function in the medium run.

The central parameters are, on the one hand, $\beta$ and $\mu$, and on the other, $\gamma$.

The parameters $\beta$ and $\mu$ determine (together with $\sigma$, which plays a minor role) the average level of capital accumulation and thus the average marginal product of capital, i.e. the average risky rate. In general, both parameters matter. In the linear production case however, the marginal product of capital is independent of the level of capital, and thus depends only on $\mu$; thus, I choose $\mu$ to fit the average value of the marginal product $E R$. In the CobbDouglas case, the marginal product of capital is instead independent of $\mu$ and depends only on $\beta$; thus I choose $\beta$ to fit the average value of the marginal product $E R$. 
The parameter $\gamma$ determines, together with $\sigma$, the spread between the risky rate and the safe rate. In the absence of transfers, the following relation holds between the two rates:

$$
\ln R_{t+1}^{f}-\ln E R_{t+1}=-\gamma \sigma^{2}
$$

This relation implies however that the model suffers from a strong case of the equity premium puzzle (see for example Kocherlakota (1996)). If we think of $\sigma$ as the standard deviation of TFP growth, and assume that, in the data, TFP growth is a random walk (with drift), this implies an annual value of $\sigma_{a}$ of about 2\%, equivalently a value of $\sigma$ over the 25-year period of $10 \%$, and thus a value of $\sigma^{2}$ of $1 \%$. Thus, if we think of the annual risk premium as equal to, say, $5 \%$, which implies a value of the right hand side of 1.22 , this implies a value of $\gamma$, the coefficient of relative risk aversion of 122, which is clearly implausible. One of the reasons why the model fails so badly is the symmetry in the degree of uncertainty facing labor and capital, and the absence of price risk associated with holding shares (as capital fully depreciates within the 25-year period). If we take instead $\sigma$ to reflect the standard deviation of annual rates of stock returns, say $15 \%$ a year (its historical mean), and assume stock returns to be uncorrelated over time, then $\sigma$ over the 25year period is equal to $75 \%$, implying values of $\gamma$ around 2.5. There is no satisfactory way to deal with the issue within the model, so as an uneasy compromise, I choose $\sigma=20 \%$. Given $\sigma, \gamma$ is determined for each pair of average risky and safe rates. ${ }^{25}$

I then consider the effects on steady state welfare of an intergenerational transfer. The basic results are summarized in Figures 7 to 10 below.

\footnotetext{
${ }^{25}$ Extending the model to allow uncertainty to differ for capital and labor is difficult to do (except for the case where production is linear and one can easily capture capital or labor augmenting technology shocks. )
} 
Figure 7 shows the effects of a small transfer ( $5 \%$ of (pre-transfer) average saving) on welfare for the different combinations of the safe and the risky rates (reported, for convenience, as net rates at annual values, rather than as gross rates at 25-year values), in the case where $\eta=\infty$ and, thus, production is linear. In this case, the derivation above showed that, to a first order, only the safe rate mattered. This is confirmed visually in the figure. Welfare increases if the safe rate is negative (more precisely, if it is below the growth rate, here equal to zero), no matter what the average risky rate.

Figure 7: Welfare effects of a transfer of $5 \%$ of saving(linear production function)

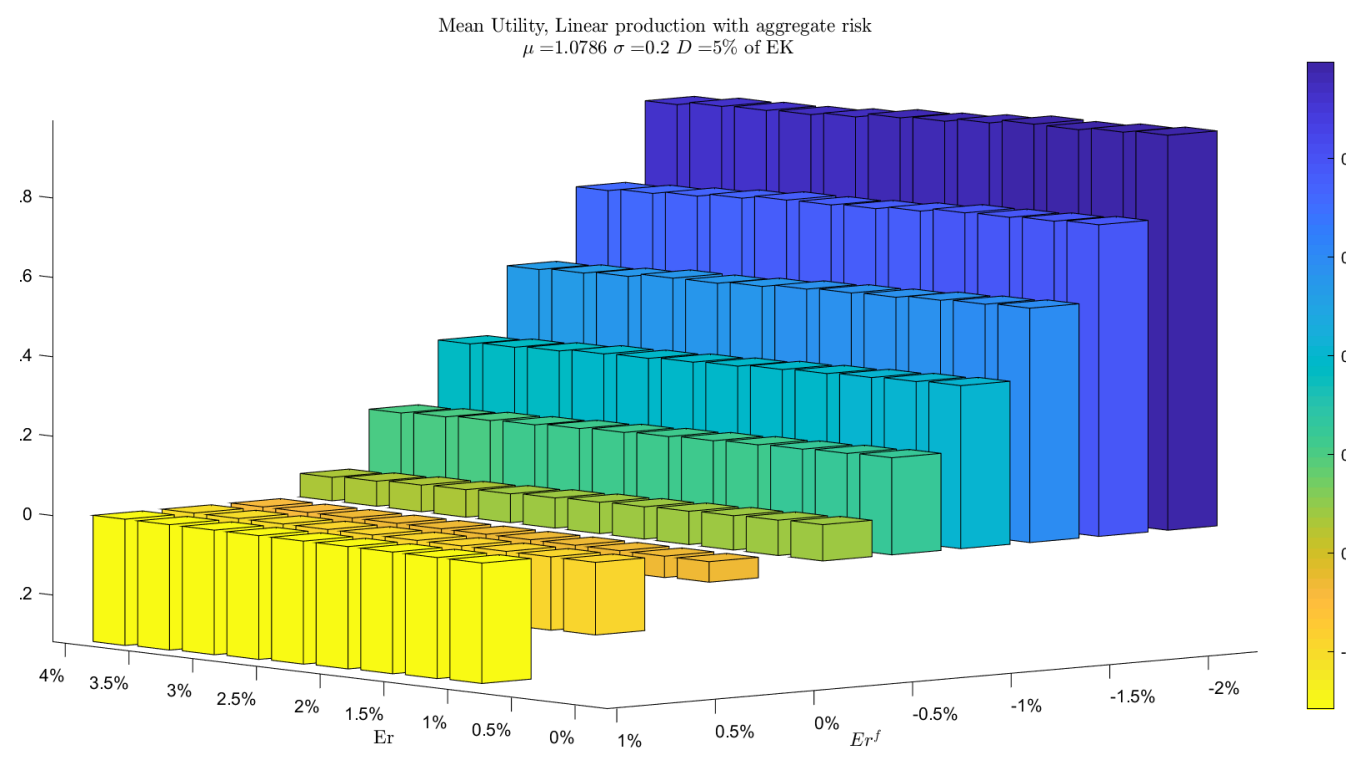

Figure 8 looks at a larger transfer (20\% of saving), again in the linear pro- 
Figure 8: Welfare effects of a transfer of $20 \%$ of saving (linear production function)

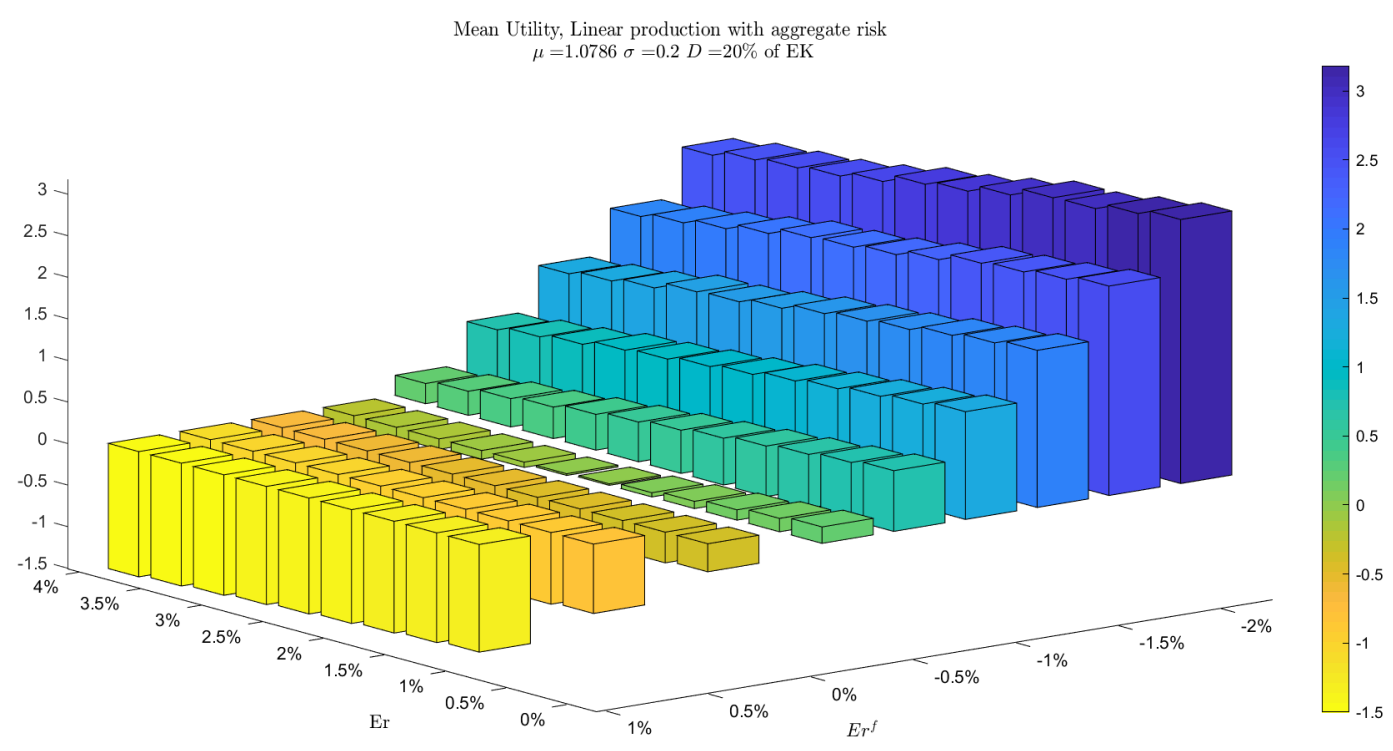


duction case. For a given $E R^{f}$, a larger $E R$ leads to a smaller welfare increase if welfare increases, and to a larger welfare decrease if welfare decreases. The reason is as follows: As the size of the transfer increases, second period income becomes less risky, so the risk premium decreases, increasing $E R^{f}$ for given average $E R$. In the limit, a transfer that led people to save nothing in the form of capital would eliminate uncertainty about second period income, and thus would lead to $E R^{f}=E R$. The larger $E R$, the faster $E R^{f}$ increases with a large transfer; for $E R$ high enough , and for $D$ large enough, $E R^{f}$ becomes larger than one, and the transfer becomes welfare decreasing.

In other words, even if the transfer has no effect on the average rate of return to capital, it reduces the risk premium, and thus increases the safe rate. At some point, the safe rate becomes positive, and the transfer has a negative effect on welfare.

Figure 9: Welfare effects of a transfer of $5 \%$ of saving. Cobb-Douglas

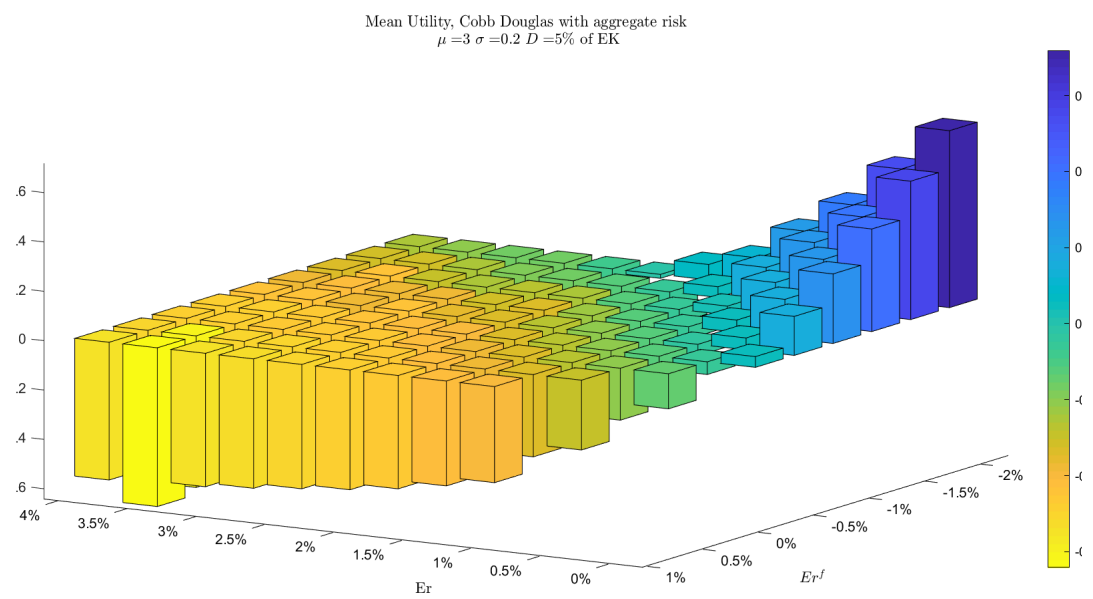


Figure 10: Welfare effects of a transfer of $20 \%$ of saving. Cobb Douglas

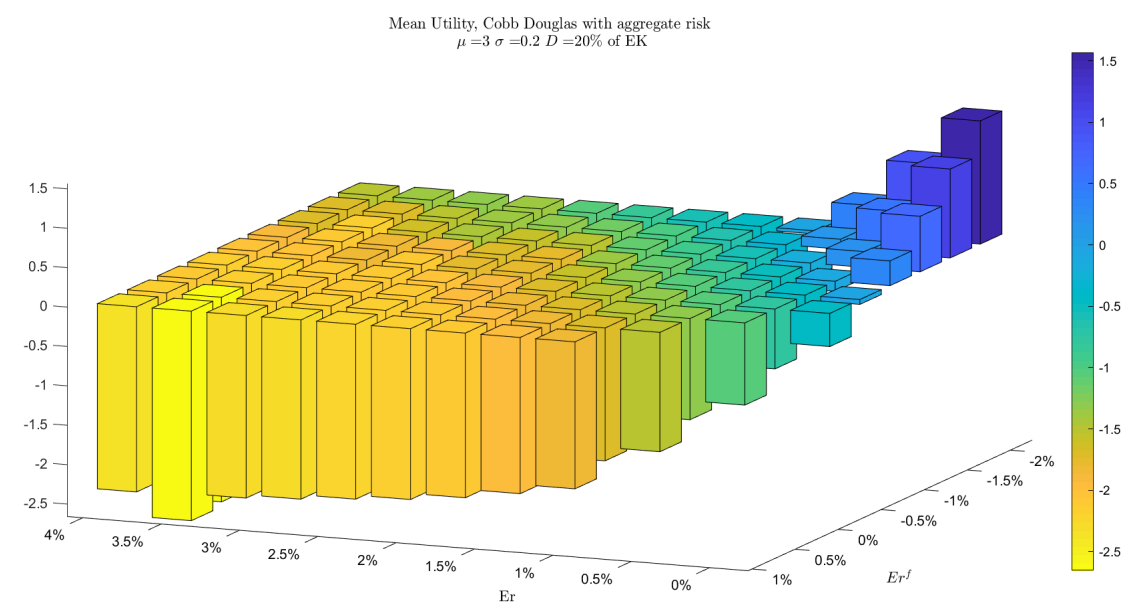

Figures 9 and 10 do the same, but now for the Cobb-Douglas case. They yield the following conclusions: Both effects are now at work, and both rates matter: A lower safe rate makes it more likely that the transfer will increase welfare; a higher risky rate makes it less likely. For a small transfer (5\% of saving), a safe rate $2 \%$ lower than the growth rate leads to an increase in welfare so long as the risky rate is less than $2 \%$ above the growth rate. A safe rate $1 \%$ lower than the growth rate leads to an increase in welfare so long as the risky rate is less than $1 \%$ above the growth rate. For a larger transfer, $(20 \%$ of saving), which increases the average $R^{f}$ closer to 1 , the trade-off becomes less attractive. For welfare to increase, a safe rate $2 \%$ lower than the growth rate requires that the risky rate be less than $1.5 \%$ above the growth rate; a safe rate of $1 \%$ below the growth rate requires that the risky rate be less than $0.7 \%$ above the growth rate. 
I have so far focused on intergenerational transfers, such as we might observe in a pay-as-you-go system. Building on this analysis, I now turn to debt, and proceed in two steps, looking first at the effects of a permanent increase in debt, then looking at debt rollovers.

Suppose the government increases the level of debt and maintains it at this higher level forever. Depending on the value of the safe rate every period, this may require either issuing new debt when $R_{t}^{f}<1$ and distributing the proceeds as benefits, or retiring debt, when $R_{t}^{f}>1$ and financing it through taxes. Following Diamond, assume that benefits and taxes are paid to, or levied on, the young. In this case, the budget constraints faced by somebody born at time $t$ are given by:

$$
\begin{gathered}
C_{1 t}=\left(W_{t}+X+\left(1-R_{t}^{f}\right) D\right)-\left(K_{t}+D\right)=W_{t}+X-K_{t}-D R_{t}^{f} \\
C_{2 t+1}=R_{t+1} K_{t}+D R_{t+1}^{f}
\end{gathered}
$$

So, a constant level of debt can be thought of as an intergenerational transfer, with a small difference relative to the case developed earlier. The difference is that a generation born at time $t$ makes a net transfer of $D R_{t}^{f}$ when young, and receives, when old, a net transfer of $D R_{t+1}^{f}$, as opposed to the one-for-one transfer studied earlier. Under certainty, in steady state, $R^{f}$ is constant and the two are equal. Under uncertainty, the variation about the terms of the intertemporal transfer implies a smaller increase in welfare than in the transfer case. Otherwise, the conclusions are very similar.

This is a good place to discuss informally a possible extension of the closed economy model, and allow the economy to be open. Start by thinking of a small open economy that takes $R^{f}$ as given and unaffected by its actions. In this case, if $R^{f}$ is less than one, an increase in debt unambiguously in- 
creases welfare. The reason is that capital accumulation is unaffected, with the increase in debt fully reflected in an increase in external debt, so the second effect characterized above is absent. In the case of a large economy such as the United States, an increase in debt will lead to both an increase in external debt and a decrease in capital accumulation. While the decrease in capital accumulation is the same as above for the world as a whole, the decrease in U.S. capital accumulation is smaller than in the closed economy. Thus, the second effect is smaller; if it was adverse, it is less adverse. This may not be the end of the story however: Other countries suffer from the decrease in capital accumulation, leading possibly to a change in their own debt policy. I leave this extension to another paper, but, in the current context in which the difference between the interest rate and the growth rate varies across countries, it is clearly of relevance today.

Let me finally turn to the effects of a debt rollover, where the government, after having issued debt and distributed the proceeds as transfers, does not raise taxes thereafter, and lets debt dynamics play out.

The government issues debt $D_{0}$. Unless the debt rollover fails, there are neither taxes nor subsidies after the initial issuance and associated transfer. The budget constraints faced by somebody born at time $t$ are thus given by:

$$
\begin{gathered}
C_{1 t}=W_{t}+X-\left(K_{t}+D_{t}\right) \\
C_{2 t+1}=R_{t+1} K_{t}+D_{t} R_{t+1}^{f}
\end{gathered}
$$

And debt follows:

$$
D_{t}=R_{t}^{f} D_{t-1}
$$


First, consider sustainability. Even if debt decreases in expected value over time, a debt rollover may fail with positive probability. A sequence of realizations of $R_{t}^{f}>1$ may increase debt to the level where $R^{f}$ becomes larger than one and then remains so, leading to a debt explosion. At some point, an adjustment will have to take place, either through default, or through an increase in taxes. The probability of such a sequence over a long but finite period of time is however likely to be small if $R^{f}$ starts far below $1 .^{26}$

This is shown in Figure 11, which plots 1000 stochastic paths of debt evolutions, under the assumption that the production function is linear, and Figure 12, under the assumption that the production function is Cobb-Douglas. In both cases, the initial increase in debt is equal to $15 \%$ of saving. ${ }^{27}$ The underlying parameters in both cases are calibrated so as to fit values of $E R$ and $E R^{f}$ absent debt corresponding to $-1 \%$ for the annual safe rate, and $2 \%$ for the annual risky rate.

Failure is defined as the point where the safe rate becomes sufficiently large and positive (so that the probability that debt does not explode becomes very small—depending on the unlikely realisation of successive large positive shocks which would take the safe rate back below the growth rate); rather arbitrarily, I choose the threshold to be $1 \%$ at an annual rate. If the debt rollover fails, I assume, again arbitrarily and too strongly, that all debt is

\footnotetext{
${ }^{26}$ In my paper with Philippe Weil (Blanchard and Weil 2001), we characterized debt dynamics, based on an epsilon increase in debt, under different assumptions about technology and preferences. We showed in particular that, under the assumptions in the text, debt would follow a random walk with negative drift. We did not however look at welfare implications.

${ }^{27}$ This may seem small relative to actual debt-to-income ratios. But note two things. The first is that, in the United States, the riskless rate is lower than the growth rate despite an existing debt-to-GDP ratio around $80 \%$, and large net social security liabilities. If there were no public debt nor social security system at all, presumably all interest rates, including the riskless rate would be substantially lower (a point made by Lukasz Rachel and Lawrence Summers (2018)). Thus, the simulation is in effect looking at additional increases in debt, starting from current levels. The second point is that, under a debt rollover, current debt is not offset by future taxes, and thus is fully net wealth. This in turn implies that it has a strong effect on capital accumulation, and in turn on both the risky and the safe rate.
} 
paid back through a tax on the young. This exaggerates the effect of failure on the young in that period, but is simplest to capture. ${ }^{28}$

In the linear case, the higher debt and lower capital accumulation have no effect on the risky rate, and a limited effect on the safe rate, and all paths show declining debt. Four periods out (100 years), all of them have lower debt than at the start.

Figure 11: Linear production function. Debt evolutions under a debt rollover $D_{0}=15 \%$ of saving

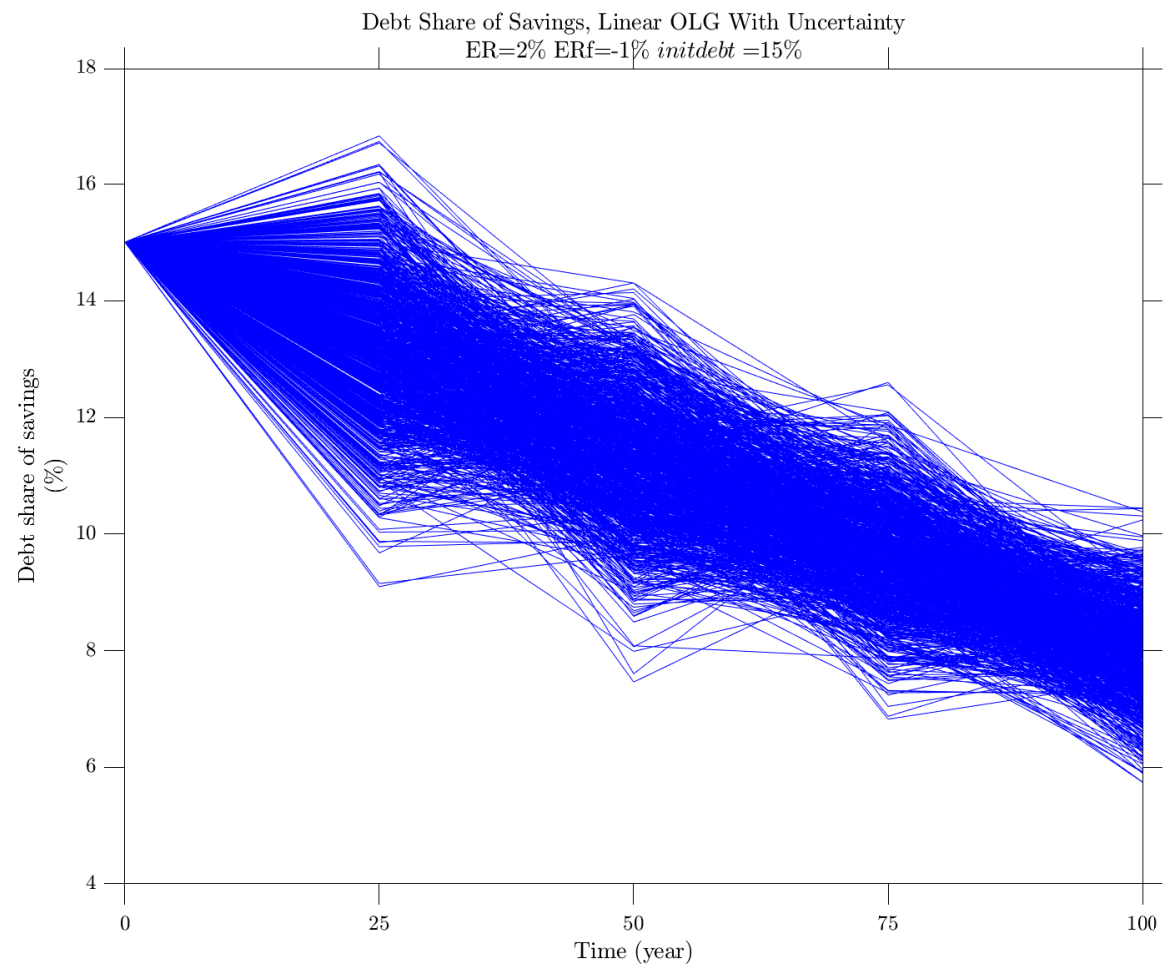

In the Cobb-Douglas case, with the same values of $E R$ and $E R^{f}$ absent

\footnotetext{
${ }^{28} \mathrm{An}$ alternative assumption would be that taxes are raised so as to stabilize debt at this level. Yet another alternative would be default on the debt. This assumption however would make public debt risky throughout, and lead to a much harder analytical problem to solve.
} 
Figure 12: Cobb-Douglas production function. Debt evolutions under a debt rollover $D_{0}=15 \%$ of saving

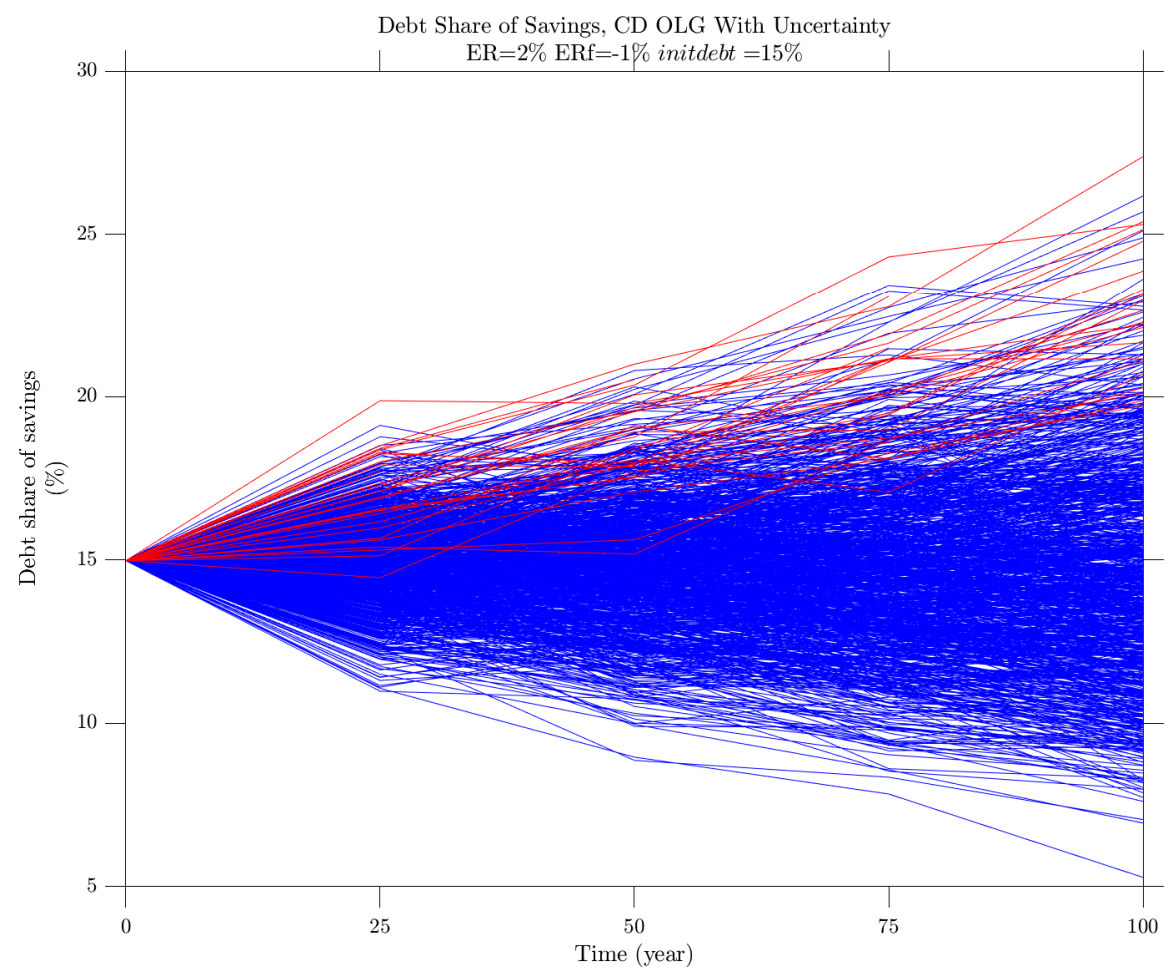


debt, bad shocks, which lead to higher debt and lower capital accumulation, lead to increases in the risky rate, and by implication, larger increases in the safe rate. The result is that, for the same sequence of shocks, now $5 \%$ of paths, fail over the first four periods- 100 years, if we take a period to be 25 years. The failing paths are represented in red.

Second, consider welfare effects: Relative to a pay-as-you-go scheme, debt rollovers are much less attractive. Remember the two effects of an intergenerational transfer. The first comes from the fact that people receive a rate of return of 1 on the transfer, a rate which is typically higher than $R^{f}$. In a debt rollover, they receive a rate of return of only $R^{f}$, which is typically less than one. At the margin, they are indifferent to holding debt or capital. There is still an inframarginal effect, a consumer surplus (taking the form of a less risky portfolio, and thus less risky second period consumption), but the positive effect on welfare is smaller than in the straight transfer scheme. The second effect, due to the change in wages and rate of return on capital, is still present, so the net effect on welfare, while less persistent as debt decreases over time, is more likely to be negative.

These effects are shown in Figures 13 and 14, which show the average welfare effects of successful and unsuccessful debt rollovers, for the linear and Cobb-Douglas cases.

In the linear case, debt rollovers typically do not fail and welfare is increased throughout. For the generation receiving the initial transfer associated with debt issuance, the effect is clearly positive and large. For later generations, while they are, at the margin, indifferent between holding safe debt or risky capital, the inframarginal gains (from a less risky portfolio) imply slightly larger utility. But the welfare gain is small (equal initially to about $0.18 \%$ and decreasing over time), compared to the initial welfare effect on the old from the initial transfer, denoted by the dot on the vertical 
Figure 13: Linear production function. Welfare effects of a debt rollover $D_{0}=$ $15 \%$ of saving

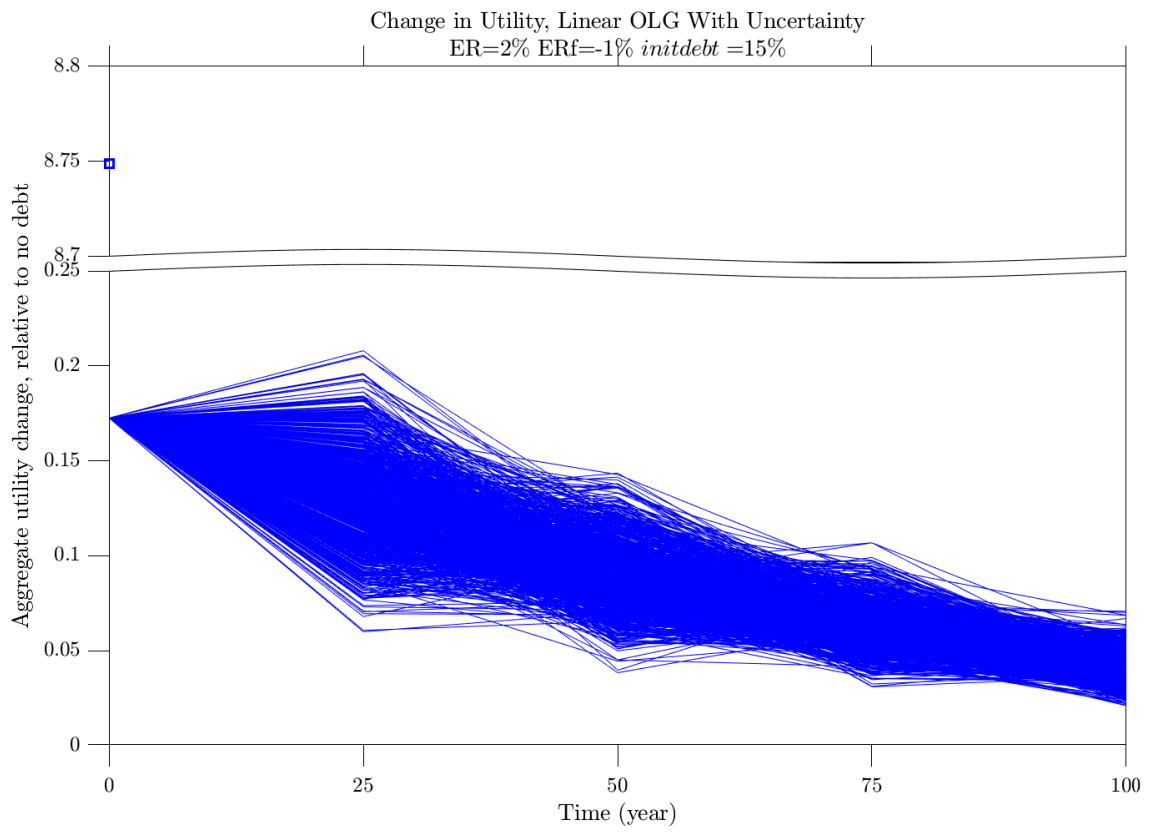


Figure 14: Cobb-Douglas production function. Welfare effects of a debt rollover $D_{0}=15 \%$ of saving

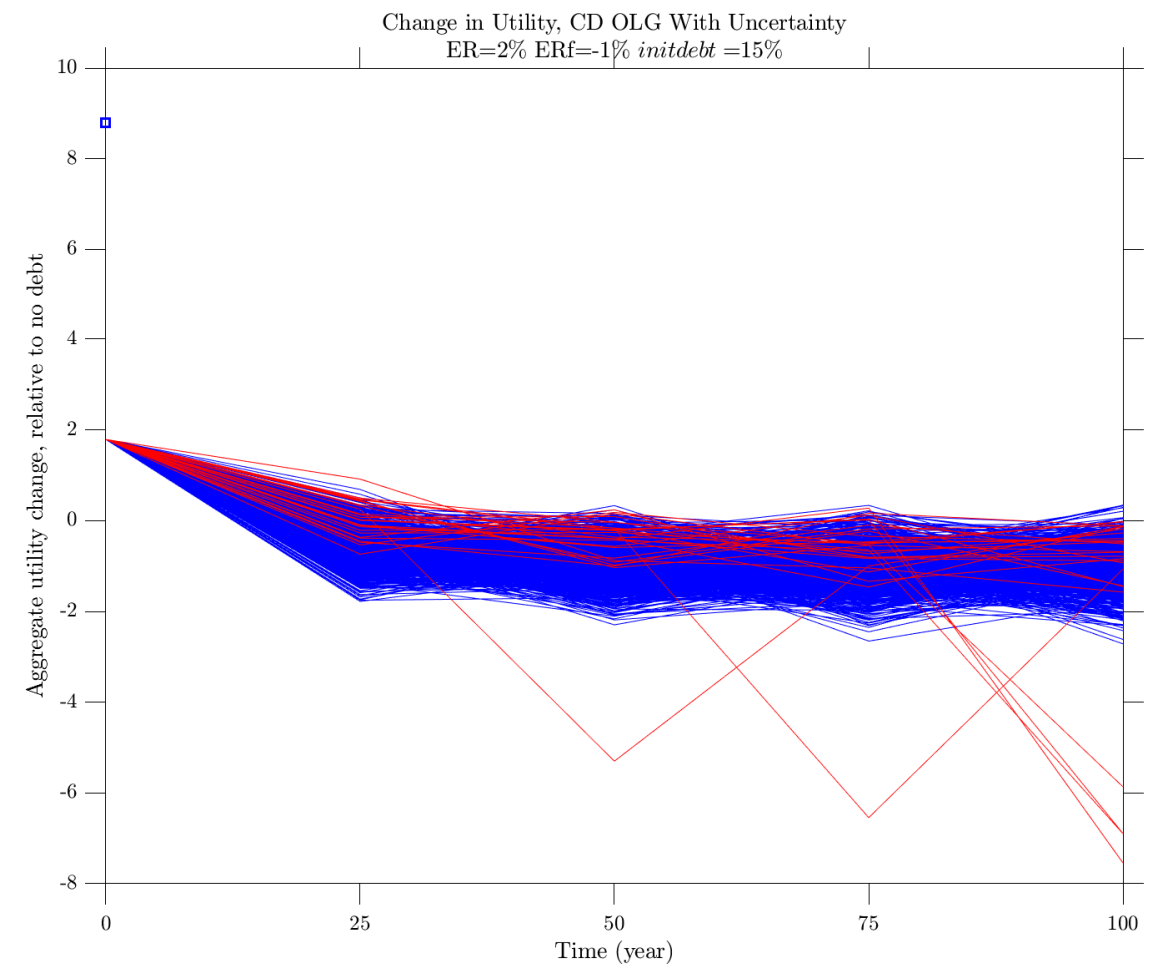


$\operatorname{axis}(8.75 \%)$.

In the Cobb-Douglas case however, this positive effect is more than offset by the price effect, and while welfare still goes up for the first generation (by about $2 \%$ ), it is typically negative thereafter. (The initial effect of the transfer on the utility of the old, denoted by a dot in the figure, is equal to $8.75 \%$ ) In the case of successful debt rollovers, the average adverse welfare cost decreases as debt decreases over time. In the case of unsuccessful rollovers, the adjustment implies a larger welfare loss when it happens. ${ }^{29}$

If we take the Cobb-Douglas example to be more representative, are these Ponzi gambles - as Ball, Elmendorf and Mankiw (1998) have called themworth it from a welfare viewpoint? This clearly depends on the relative weight the policy maker puts on the utility of different generations. If the social discount factor it uses is close to one, then debt rollovers under the conditions underlying the Cobb Douglas simulation are likely to be unappealing, and lead to a social welfare loss. If it is less than one, the large initial increase in utility may well dominate the average utility loss later. ${ }^{30}$

\section{Earnings versus marginal products}

The argument developed in the previous two sections showed that the welfare effects of an intergenerational transfer-or an increase in debt, or a debt rollover-depend both on how low the average safe rate and how high the av-

\footnotetext{
${ }^{29}$ Note that, in figure 14, the cost of adjustment when a rollover is unsuccessful increases over time. This is because the average value of debt, conditional on exceeding the threshold, increases for some time. Initially, only a few paths reach the threshold, and the value of debt, conditional on exceeding the threshold, is very close to the threshold. As the distribution becomes wider, the value of debt, conditional on crossing the threshold increases. As the distribution eventually stabilizes, the welfare cost also stabilizes. In the simulation, this happens after approximately 6 periods, or 150 years.

${ }^{30}$ The idea that a government wants to embark on a path that may fail may feel unacceptable. But this is in fact the case for many policy decisions, such as for example the choice of minimum capital ratios for banks.
} 
erage marginal product of capital are relative to the growth rate. The higher the average marginal product of capital, for a given safe rate, the more adverse the effects of the transfer. In the simulations above (reiterating the caveats about how seriously one should take the quantitative implications of that model), the welfare effects of an average marginal product far above the growth rate typically dominated the effects of an average safe rate slightly below the growth rate, implying a negative effect of the transfer (or of debt) on welfare.

Such a configuration would seem to be the empirically relevant one. Look at Figure 15. The red line gives the evolution of the ratio of pre-tax earnings of U.S. non-financial corporations, defined as their net operating surplus, to their capital stock measured at replacement cost, since 1950. Note that, while this earnings rate declined from 1950 to the late 1970s, it has been rather stable since then, around a high $10 \%$, so 6 to $8 \%$ above the growth rate. (see Appendix D for details of construction and sources)

Look at the blue line however. It shows the evolution of the ratio of the same earnings series, now to the market value of the same firms, constructed as the sum of the market value of equity plus other liabilities minus financial assets. Note how it has declined since the early 1980s, going down from roughly $10 \%$ then to about $5 \%$ today. Put another way, the ratio of the market value of firms to their measured capital at replacement cost, known as Tobin's q, has roughly doubled since the early 1980s, going roughly from 1 to 2.

There are two ways of explaining this diverging evolution; both have implications for the average marginal product of capital, and, as result, for the welfare effects of debt. ${ }^{31}$ Both have been and are the subject of much research, triggered by an apparent increase in markups and concentration in

\footnotetext{
${ }^{31}$ There is actually a third way, which is that stock prices do not reflect fundamentals. While this is surely relevant at times, it is unlikely to be true over a 40 year period.
} 
many sectors of the U.S. economy (e.g. DeLoecker and Eeckhout (2017), Gutièrrez and Philippon (2017), Philippon (2018), Barkai (2018), Farhi and Gouriou (2018).)

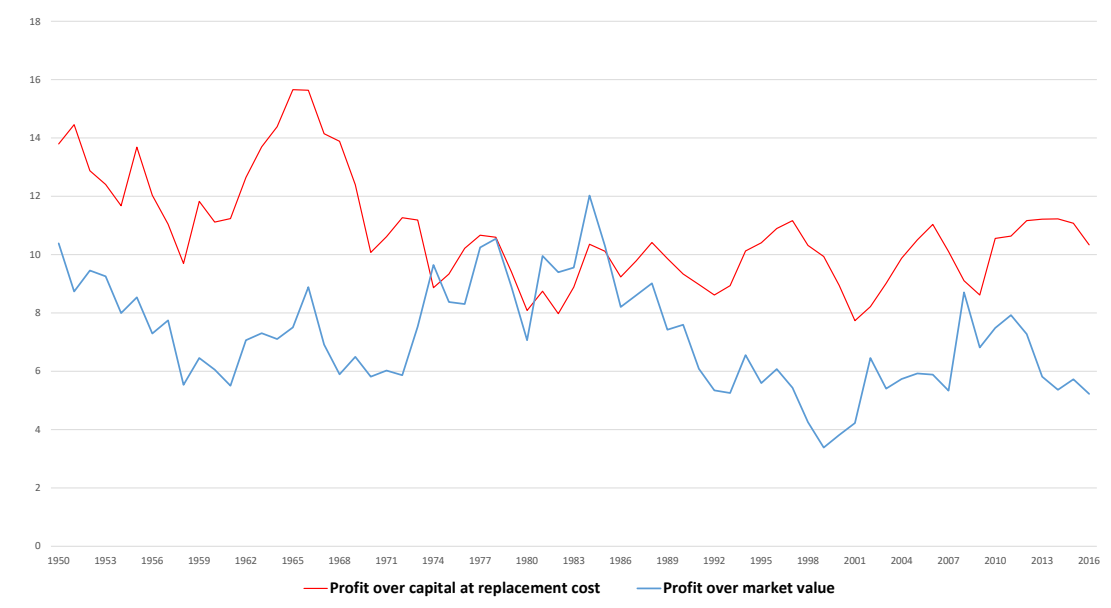

Figure 15: Earnings over replacement cost, Earnings over market value since 1950

The first explanation is unmeasured capital, reflecting in particular intangible capital. To the extent that the true capital stock is larger than the measured capital stock, this implies that the measured earnings rate overstates the true rate, and by implication overstates the marginal product of capital. A number of researchers have explored this hypothesis, and their conclusion is that, even if the adjustment already made by the Bureau of Economic Analysis is insufficient, intangible capital would have to be implausibly large to reconcile the evolution of the two series: Measured intangible capital as a share of capital has increased from $6 \%$ in 1980 to $15 \%$ today. Suppose it had in fact increased to $25 \%$. This would only lead only to a $10 \%$ increase in measured capital, far from enough to explain the divergent evolutions of the two series. ${ }^{32}$

\footnotetext{
${ }^{32}$ Further discussion can be found in Barkai 2018.
} 
The second explanation is increasing rents, reflecting in particular the increasing relevance of increasing returns to scale and increased concentration. ${ }^{33}$. If so, the earnings rate reflects not only the marginal product of capital, but also rents. By implication, the market value of firms reflects not only the value of capital but also the present value of rents. If we take all of the increase in the ratio of the market value of firms to capital at replacement cost to reflect an increase in rents, the doubling of the ratio implies that rents account for roughly half of earnings. ${ }^{34} 35$

As with many of the issues raised in this lecture, many caveats are in order, and they are being taken on by current research. Movements in Tobin's $\mathrm{q}$, the ratio of market value to capital, are often difficult to explain. ${ }^{36}$ Yet, the evidence is fairly consistent with a decrease in the average marginal product of capital, and by implication, a smaller welfare cost of debt.

\footnotetext{
${ }^{33}$ For a parallel discussion, and similar conclusions, see Hall (2018)

${ }^{34} \mathrm{~A}$ rough arithmetic exercise: Suppose $V=q K+P D V(R)$, where $V$ is the value of firms, $q$ is the shadow price of capital, $R$ is rents. The shadow price of capital is in turn given by $q=P D V(M P K) / K$. Look at the medium run where adjustment costs have worked themselves out, so $q=1$. Then $V / K-1=P D V(R) / P D V(M P K)$. If $V / K$ doubles from 1 to 2, then this implies that $P D V(R)=P D V(M P K)$, so rents account for half of total earnings.

${ }^{35} \mathrm{An}$ interesting and provocative paper by Geerolf (2017) extends this exercise to a number of advanced economies. Instead of comparing the earnings rate and the growth rate as I do here, he follows Abel et al (1989) in comparing capital income and investment. He concludes that, assuming that there are no rents so $V / K=1$, Korea had capital income lower than investment in all years since 1970, and that, if one allows for rents and assumes for example $V / K=1.5$, the same is true for 9 out of 12 countries in his sample. If his conclusions are correct, they deliver a result stronger than the one in the text, namely that public debt is unambiguously welfare improving in Korea, and, under the assumption that $V / K=1.5$, it is likely to be welfare improving in a number of other advanced economies.

${ }^{36}$ In particular, what makes me uncomfortable with the argument is the behavior of Tobin's q from 1950 to 1980, which roughly halved. Was it because of decreasing rents then?
} 


\section{A broader view. Arguments and counterarguments}

So far, I have considered the effects of debt when debt was used to finance intergenerational transfers in a full employment economy. This was in order to focus on the basic mechanisms at work. But it clearly did not do justice to the potential benefits of debt finance, nor does it address other potential costs of debt left out of the model. The purpose of this last section is to discuss potential benefits and potential costs. As this touches on many aspects of the economy and many lines of research, it is informal, more in the way of remarks and research leads than definitive answers about optimal debt policy.

Start with potential benefits.

Even within the strict framework above, the focus on steady state utility (in the case of intergenerational transfers, or of a permanent increase in debt) ignored the transition to the steady state, and in particular, the effect on the initial ("old") generation of the initial transfer (in the case of intergenerational transfers), or the initial spending financed by debt (in the case of constant debt). Steady state utility is indeed the correct variable to focus if the policy maker values the current and all future generations equally. To the extent however that the social welfare discount rate is less than one, a negative effect on steady state welfare may be more than offset by the increase in utility of the initial generation. As argued above, the same argument applies to debt rollovers: The initial increase in utility may more than offset negative utility effects later on. ${ }^{37}$

\footnotetext{
${ }^{37} \mathrm{~A}$ positive initial effect, and a negative steady state effect, imply that there is a social welfare discount factor such that the effect on social welfare, defined as the present value of current and future expected utility becomes positive. While I have computed it for the intergenerational transfers, constant debt, and debt rollover cases presented earlier, I do
} 
Going beyond the framework above, a standard argument for deficit finance in a country like the United States is its potential role in increasing demand and reducing the output gap when the economy is in recession. The financial crisis, and the role of both the initial fiscal expansion and the later turn to fiscal austerity, have led to a resurgence of research on the topic. Research has been active on four fronts:

The first has revisited the size of fiscal multipliers. Larger multipliers imply a smaller increase in debt for a given increase in output. Looking at the Great Recession, two arguments have been made that multipliers were higher during that time. First, the lower ability to borrow by both households and firms implied a stronger effect of current income on spending, and thus a stronger multiplier. Second, at the effective lower bound, monetary authorities did not feel they should increase interest rates in response to the fiscal expansion. ${ }^{38}$

The second front, explored by DeLong and Summers (2012) has revisited the effect of fiscal expansions on output and debt in the presence of hysteresis. They have shown that even a small hysteretic effect of a recession on later output might lead a fiscal expansion to actually reduce rather than increase debt in the long run, with the effect being stronger, the stronger the multipliers and the lower the safe interest rate. ${ }^{39}$ Note that this is a different argument from the argument developed in this paper: The proposition is that a fiscal expansion may not increase debt, while I argue that an increase in debt may have small fiscal and welfare costs. The two arguments

not present the results here The model above is too crude to allow for credible quantitative estimates.

${ }^{38}$ For a review of the empirical evidence up to 2010 see Ramey (2011). For more recent contributions, see, for example, Mertens (2018) on tax multipliers, Miyamoto et al (2018) on the multipliers under the zero lower bound in Japan, and the debate between Auerbach and Gorodnichenko (2012) and Ramey and Zubairy (2018)

${ }^{39}$ I examined the evidence for or against hysteresis in Blanchard (2018). I concluded that the evidence was not strong enough to move priors, for or against, very much. 
are clearly complementary however.

The third front has been that public investment has been too low, often being the main victim of fiscal consolidation, and that the marginal product of public capital is high. The relevant point here is that what should be compared is the risk-adjusted social rate of return on public investment to the risk-adjusted rate of return on private capital, i.e. the safe rate.

The fourth front has explored the role of deficits and debt if we have indeed entered a long-lasting period of secular stagnation, in which large negative safe interest rates would be needed for demand to equal potential output but monetary policy is constrained by the effective lower bound. In that case, budget deficits may be needed on a sustained basis to achieve sufficient demand and output growth. Some argue that this is already the case for Japan, and may become the case for other advanced economies. Here, the results of this paper directly reinforce this argument. In this case, not only are budget deficits needed to eliminate output gaps, but, because safe rates are likely to be far below potential growth rates, the welfare costs of debt may be small or even altogether absent.

Let me however concentrate on the potential costs of debt, and on some counterarguments to the earlier conclusions that debt may have low fiscal or welfare costs. I can think of three main counterarguments:

The first is that the safe rate may be artificially low, so the welfare implications above do not hold. It is generally agreed that U.S. government bonds benefit not only from low risk, but also from a liquidity discount, leading to a lower safe rate than would otherwise be the case. The issue however is whether this discount reflects technology and preferences or, instead, distortions in the financial system. If it reflects liquidity services valued by households and firms, then the logic of the earlier model applies: The safe rate is now the liquidity-adjusted and risk-adjusted equivalent of 
the marginal product of capital and is thus what must be compared to the growth rate. If however, the liquidity discount reflects distortions-for example financial repression forcing financial institutions to hold a certain proportion of their portfolios in government bonds-then indeed the safe rate is no longer the appropriate rate to compare to the growth rate. It may be welfare improving in this case to reduce financial repression even if this leads to a higher safe rate, and a higher cost of public debt. ${ }^{40}$ Straight financial repression is no longer relevant for the United States, but various agency issues internal to financial institutions as well as financial regulations such as minimum liquidity ratios, may have some of the same effects.

The second counterargument is that the future may be different from the past, and that, despite the long historical record, the safe interest rate may become consistently higher than the growth rate. History may indeed not be a reliable guide to the future. As the debate on secular stagnation and the level of the long run Wicksellian rate (the safe rate consistent with unemployment remaining at the natural rate) indicate, the future is indeed uncertain. It may be that some of the factors underlying low rates will fade over time. Or it may be because public debt increases to the point where the equilibrium safe rate actually exceeds the growth rate. In the formal model above, a high enough level of debt, and the associated decline in capital accumulation, eventually leads to an increase in the safe rate above the growth rate, leading to positive fiscal costs and higher welfare costs. Indeed, the trajectory of deficits under current fiscal plans is indeed worrisome. Estimates by Sheiner (2018) for example suggest, that even under the assumption that the safe rate remains below the growth rate, we may see an increase in the ratio of debt to GDP of close to $60 \%$ of GDP between now and 2043. If so, using a standard (but admittedly rather uncertain as well) back-of-the-envelope

\footnotetext{
${ }^{40}$ This trade-off is also present in Angeletos et al (2016).
} 
number that an increase in debt of $1 \%$ of GDP increases the safe rate by $2-3$ basis points, this would lead to an increase in the safe rate of $1.2 \%$ to $1.8 \%$, enough to reverse the inequality between the safe rate and the growth rate.

The evidence on indexed bonds suggests however two reasons to be relatively optimistic about the sign of the inequality. The first is that, to the extent that the U.S. government can finance itself through inflation-indexed bonds, it can actually lock in a real rate of $1.1 \%$ over the next 30 years, a rate below even pessimistic forecasts of growth over the same period. The second is that investors seem to give a small probability to a major increase in rates. Looking at 10-year inflation-indexed bonds, and using realized volatility as a proxy for implied volatility (option markets are not deep enough to derive implied volatility directly), suggests that the market puts the probability that the rate will be higher than $200 \mathrm{bp}$ in five years around $5-15 \% .{ }^{41}$

In short, one can surely not exclude the possibility that debt will indeed be more costly in the future, and the safe rate may exceed the growth rate. The welfare implications however are continuous, and for reasonably small positive differences between the interest rate and the growth rate, the welfare costs will remain small. The basic intuition remains the same: The safe rate is the risk-adjusted rate of return on capital. If it is higher but not much higher than the growth rate, lower capital accumulation may not have major adverse welfare effects.

The third counterargument relies on the existence of multiple equilibria and may be the most difficult to counter. ${ }^{42}$ Suppose that the model above is right, and that investors believe debt to be safe and are willing to hold it

\footnotetext{
${ }^{41}$ The daily standard deviation is around $2-3$ basis points, implying a 5 -year standard deviation of 70-105 basis points. This implies that the probability that the rate, which today is 90 basis points, is larger than 200 basis points is $5-15 \%$.

${ }^{42}$ It feels less relevant for the United States than for other countries, in particular emerging markets. But, as the U.S. debt to GDP ratio increases, it may become part of the discussion even in the United States.
} 
at the safe rate. In this case, the fiscal cost of debt may indeed be zero, and the welfare cost may be small. If however, investors believe that debt is risky and ask for a risk premium to compensate for that risk, debt payments will be larger, and debt will indeed be risky, and investors' expectations may be self-fulfilling.

The mechanics of such fiscal multiple equilibria were first characterized by Calvo (1988), later on by Giavazzi and Pagano (1990), and more recently by Lorenzoni and Werning (2018). In this case, over a wide range of debt, there may be two equilibria, with the good one being the one where the rate is low, and the bad one characterized by a high risk premium on public debt, and a higher rate. ${ }^{43}$

The question is what practical implications this has for debt levels.

The first question is whether there is a debt level sufficiently low as to eliminate the multiplicity. If we ignore strategic default, there must be some debt level low enough that the debt is effectively safe and there is only one equilibrium. The proof is by contradiction: Suppose investors worry about risk and increase the required rate. As the required rate increases, the state may indeed default. But suppose that, even if it defaults, debt is low enough that, while it cannot pay the stated rate, it can pay the safe rate. This in turn implies that investors, if they are rational, should not and will not worry about risk.

This argument however raises two issues. First, it may be difficult to assess what such a safe level of debt is: it is likely to depend on the nature of the government, its ability to increase and maintain a primary surplus. Second, the safe level of debt may be very low, much lower than current levels of debt in the United States or in Europe. If multiple equilibria are present at,

\footnotetext{
${ }^{43}$ Under either formal or informal dynamics, the good equilibrium is stable, while the bad equilibrium is unstable. However, what may happen in this case, is that the economy moves to a position worse than the bad equilibrium, with interest rates and risk premia increasing over time from then on.
} 
say $100 \%$ of GDP, they are likely to still be present at $90 \%$ as well; going however from $100 \%$ of GDP to $90 \%$ requires a major fiscal consolidation and, if the fiscal consolidation cannot be fully offset by expansionary monetary policy, an economic contraction. As Giavazzi and Pagano, and Lorenzoni and Werning, have shown, other dimensions of debt and fiscal policy, such as the maturity of debt or the aggressiveness of the fiscal rule in response to higher interest rates, are likely to be more important than the level of debt itself, and help eliminate the bad equilibrium. To be more concrete, it may be that, rather than embarking on fiscal austerity if it cannot be fully offset by looser monetary policy, it is better to rely on an aggressive contingent fiscal rule to eliminate the bad equilibrium.

\section{Conclusions}

In this lecture, I have looked at the fiscal and welfare costs of higher debt in an economy where the safe interest rate is less than the growth rate. I have argued that this is a relevant empirical configuration, and indeed has been the norm rather than the exception in the United States in the past. I have argued that both the fiscal and welfare costs of debt may then be small, smaller than is generally taken as given in current policy discussions. I have considered a number of counterarguments, which are indeed valid, and may imply larger fiscal and welfare costs. The purpose of this lecture is most definitely not to argue for higher debt per se, but to allow for a richer discussion of debt policy and appropriate debt rules than is currently the case. 


\section{References}

[1] Andrew Abel, N. Gregory Mankiw, Lawrence Summers, and Richard Zeckhauser. Assessing dynamic inefficiency: Theory and evidence. Review of Economic Studies, 56:1-20, 1989.

[2] S. Rao Aiyagari and Ellen McGrattan. The optimum quantity of debt. Journal of Monetary Economics, 42(3):447-469, October 1998.

[3] George Marios Angeletos, Fabrice Collard, and Harris Dellas. Public debt as private liquidity; Optimal policy. October 2016. Manuscript, MIT.

[4] Alan Auerbach and Yury Gorodnichenko. Measuring the output responses to fiscal policy. American Economic Journal: Economic Policy, 4(2):1-27, 2012.

[5] Laurence Ball, Douglas Emendorf, and N. Gregory Mankiw. The deficit gamble. Journal of Money, Credit and Banking, 30(4):699-720, November 1998.

[6] Simcha Barkai. Declining labor and capital shares. October 2018. Manuscript, LSE.

[7] Philip Barrett. Interest-growth differentials and debt limits in advanced economies. April 2018. IMF Working Paper.

[8] Olivier Blanchard. Should we reject the natural rate hypothesis? Journal of Economic Perspectives, 32(1):97-120, Winter 2018.

[9] Olivier Blanchard and Philippe Weil. Dynamic efficiency, the riskless rate, and debt Ponzi games under uncertainty. Advances in Macroeconomics, pages 1-23, November 2001. 
[10] Ricardo Caballero, Emmanuel Farhi, and Pierre-Olivier Gourinchas. Rents, technical change, and risk premia. Accounting for secular trends in interest rates, returns on capital, earning yields, and factor shares. American Economic Review, 107(5):614-620, May 2017. a.

[11] Ricardo Caballero, Emmanuel Farhi, and Pierre-Olivier Gourinchas. The safe assets shortage conundrum. Journal of Economic Perspectives, 31(3):29-46, Summer 2017. b.

[12] Guillermo Calvo. Servicing the public debt: The role of expectations. American Economic Review, 78(4):647-661, September 1988.

[13] Carlos Carvalho, Andrea Ferrero, and Fernanda Nechio. Demographics and real interest rates: Inspecting the mechanism. European Economic Review, 88:208-226, September 2016.

[14] Jan De Loecker and Jan Eeckhout. The rise of market power and the macroeconomic implications. August 2017. Manuscript, Princeton.

[15] Bradford DeLong and Lawrence Summers. Fiscal policy in a depressed economy. Brookings Papers on Economic Activity, 2012:233-297, Spring 2012.

[16] Peter Diamond. National debt in a neoclassical growth model. American Economic Review, 55(5-1):1126-1150, December 1965.

[17] Larry Epstein and Stanley Zin. Substitution, risk aversion, and the temporal behavior of consumption and asset returns. A theoretical framework. Handbook of the Fundamentals of Financial Decision Making, pages 207-239, 2013.

[18] Emmanuel Farhi and Francois Gouriou. Accounting for macro finance 
trends. Market power, intangibles, and risk premia. November 2018. NBER working paper 25282.

[19] Emmanuel Farhi and Jean Tirole. Bubbly liquidity. Review of Economic Studies, 79:678-706, 2012.

[20] Daniel Feenberg, Clinton Tepper, and Ivo Welch. Are interest rates really low? January 2018. NBER working paper 24258.

[21] Francois Geerolf. Reassessing dynamic efficiency. July 2017. Manuscript, UCLA.

[22] Francesco Giavazzi and Marco Pagano. Confidence crisis and public debt management. 1990. Capital Markets and Debt Management. Mario Draghi and Rudiger Dornbusch (eds.) Cambridge University Press.

[23] German Gutierrez and Thomas Philippon. Declining competition and investment in the u.s. November 2017. Manuscript, New York University.

[24] Robert Hall. New evidence on market power, profit, concentration, and the role of mega-firms in the U.S. economy. September 2018. Manuscript, Stanford University.

[25] Jens Hilscher, Alon Ravv, and Ricardo Reis. Inflating away the public debt? An empirical assessment. July 2018. Manuscript,LSE.

[26] Oscar Jordá, Katharina Knoll, Dmitry Kuvshinov, Moritz Schularick, and Alan Taylor. The rate of return on everything, 1870-2015. December 2017. Federal Reserve Bank of San Francisco Working Paper 2017-25.

[27] Narayana Kocherlakota. The equity premium: It's still a puzzle. Journal of Economic Literature, 34(1):42-71, March 1996. 
[28] Guido Lorenzoni and Ivan Werning. Slow moving debt crises. July 2018. Manuscript, MIT.

[29] Kurt Lunsford and Kenneth West. Some evidence on secular drivers of U.S. safe real rates. November 2018. NBER working paper 25288.

[30] Alberto Martin and Jaume Ventura. Managing credit bubbles. Journal of the European Economic Association, 14(3):753-789, March 2016.

[31] Paolo Mauro, Rafael Romeu, Ariel Binder, and Asad Zaman. A modern history of fiscal prudence and profligacy. Journal of Monetary Economics, 76:55-70, 2015.

[32] Neil Mehrotra. Implications of low productivity growth for debt sustainability. 1(2), November 2017. Manuscript, Brown University.

[33] Neil Mehrotra and Dmitriy Sergeyev. Debt sustainability in a low interest world. 1(2), December 2018. Manuscript, Brookings Institution.

[34] Karel Mertens. The near term growth impact of the Tax Cuts and Jobs Act. March 2018. FRB Dallas.

[35] Wataru Miyamoto, Thuy Lan Nguyen, and Dmitry Sergeyev. Government spending multipliers under the zero lower bound: Evidence from Japan. American Economic Journal: Macroeconomics, 10(3):247-277, 2018.

[36] Thomas Philippon. A primer on concentration, investment, and growth. August 2017. Prepared for the Jackson Hole Economic Policy Symposium.

[37] Lukasz Rachel and Thomas Smith. Secular drivers of the global real interest rate. 1(2), December 2015. Staff Working Paper, Bank of England. 
[38] Lukasz Rachel and Lawrence Summers. The equilibrium real interest rate in advanced economies: The role of of government policies and current account imbalances. July 2018. Manuscript, Harvard and LSE.

[39] Valerie Ramey. Can government purchases stimulate the economy? Journal of Economic Literature, 49(3):673-685, September 2011.

[40] Valerie Ramey and Sarah Zubairy. Government spending multipliers in good times and in bad: Evidence from U.S. historical data. 2018. Manuscript, forthcoming, JPE.

[41] Paul Schmelzing. Eight centuries of global real rates and the suprasecular decline, 1311-2018. November 2019. Manuscript, Harvard University.

[42] Louise Sheiner. Effects of low productivity growth on fiscal sustainability in the united states. May 2018. Manuscript, Peterson Institute for International Economics.

[43] Robert Shiller. Market Volatility. MIT Press, 1992.

[44] Lawrence Summers. What is the social return to capital investment? pages 113-141, 1990. in "Growth, Productivity, and Unemployment, Essays in honor of Robert Solow", Peter Diamond editor, MIT Press.

[45] Lawrence Summers. Demand side secular stagnation. American Economic Review Papers and Proceedings, 105:60-65, May 2015.

[46] Robert Waldman. Dynamic inefficiency when the expected return on capital is greater than the growth rate. 2016. www.scribd.com/ document/397505245.

[47] Philippe Weil. Nonexpected utility in macroeconomics. Quarterly Journal of Economics, 105(1):29-42, February 1990. 
[48] Philippe Weil. Overlapping generations: The first Jubilee. Journal of Economic Perspectives, 22(4):115-134, 2008.

[49] Itzhak Zilcha. Characterizing efficiency in stochastic overlapping generations models. Journal of Economic Theory, 55:1-16, 1991. 